\title{
ENTERRAMIENTOS DE LA ANTIGÜEDAD TARDÍA EN VALENTIA
}

\author{
ALBERT RIBERA I LACOMBA \\ RAFAELA SORIANO SÁNCHEZ \\ Ayuntamiento de Valencia
}

\author{
A Vicent, Castell, Investigador y defensor \\ del patrimonio histórico de la ciudad de Valencia
}

\begin{abstract}
Con el presente trabajo damos a conocer una serie de enterramientos tardo-antiguos de Valentia y sus alrededores, hasta ahora inéditos. Por una parte, trataremos del descubrimiento, a principios de la década de los sesenta, de un mausoleo del siglo IV d. C. Por otra, expondremos los resultados de las recientes excavaciones llevadas a cabo por el Servicio de Investigación Arqueológica Municipal (SIAM) del Ayuntamiento de Valencia, en el convento de Sant Vicent de la Roqueta y en la calle del Mar.
\end{abstract}

This paper deals with some unpublished late roman burials at Valentia and its environs. We specially study a mausoleum discovered in the years 60 's and the new excavation which the S. I. A. M. of Valencia has carried out in the Convent of Sant Vicent de la Roqueta and the Mar Street.

Una de las etapas históricas de la ciudad de Valencia que presentan más lagunas y problemas es, sin ninguna duda, la que abarca desde los últimos momentos de la dominación romana a la instauración del Califato de Córdoba. En este contexto, pues, son muy valiosos todos los datos que se puedan aportar para ir reconstruyendo esta parcela tan incompleta de nuestro pasado.

Con el presente trabajo damos a conocer una serie de enterramientos tardo-antiguos de Valentia y sus alrededores, hasta ahora inéditos. Por una parte, trataremos del descubrimiento, a principios de la década de los sesenta, de un mausoleo del siglo IV d. C. Por otra, expondremos los resultados de las recientes excavaciones llevadas a cabo por el Servicio de Investigación Arqueológica Municipal (SIAM) del Ayuntamiento de Valencia, en el convento de Sant Vicent de la Roqueta y en la calle del Mar (fig. 1).

\section{EL MAUSOLEO DEL «CAMÍ DEL MOLÍ DELS FRARES $»$ (ORRIOLS)}

En noviembre del año 1960 se notificó a la alcaldía de la ciudad de Valencia el descubrimiento de unas sepulturas, en el transcurso de unas obras, en el «Camí del Molí dels Frares», dentro de la barriada de Orriols, al Norte de la ciudad, muy cerca del convento de San Miguel de los Reyes y junto a la antigua carretera de Barcelona, cuyo trazado debe corresponder a la Vía Augusta. Alertado el SIAM, se personó en el lugar de las obras don José Llorca, por entonces encargado de las excavaciones arqueológicas en la ciudad, que procedió a excavar el sector del solar en el que aparecían los restos funerarios. Pero, como era habitual en los trabajos arqueológicos de esta época, la información que poseemos es bastante reducida y algo confusa. Contamos sólo con tres fotografías (lám. I, 1), unos cuantos cro- 


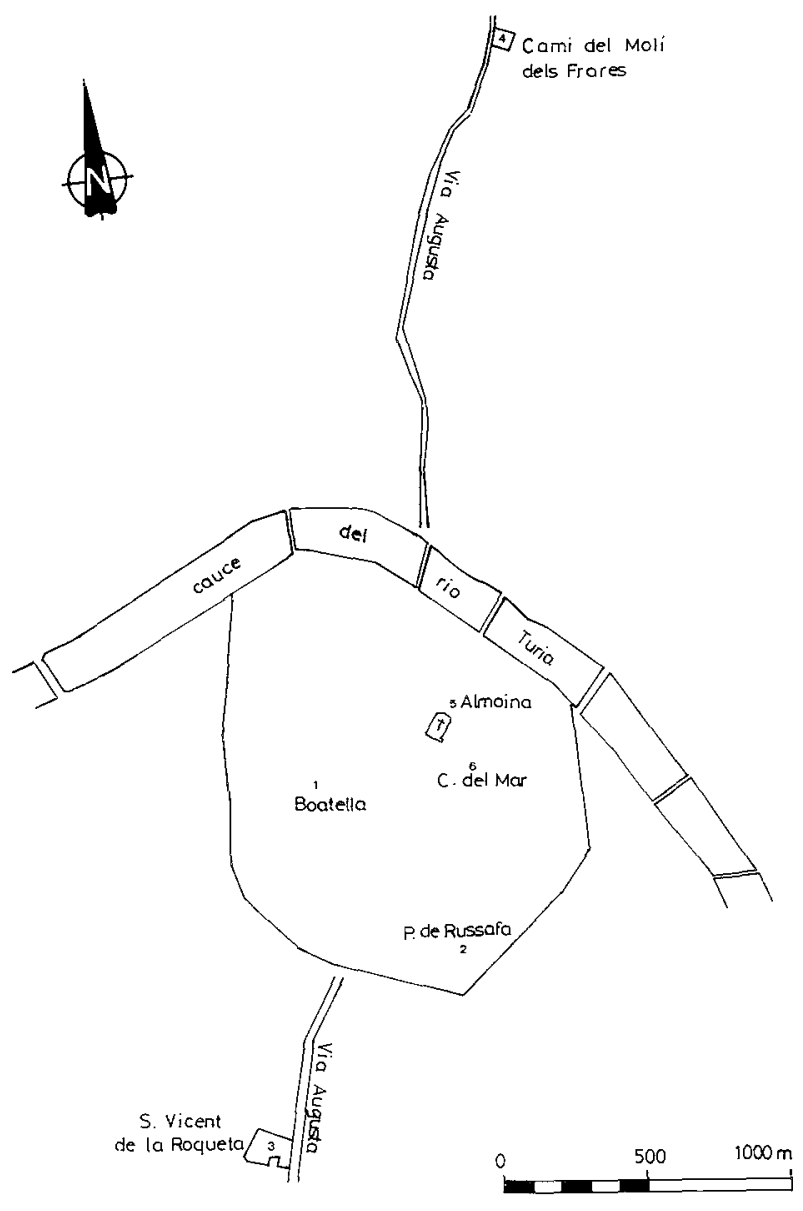

Fig. 1.-Centro histórico de Valencia (recinto del siglo XIV). Zonas de necrópolis tardorromanas.

quis y el diario de excavaciones que realizara Llorca. Por tanto, dado lo reducido y la calidad de esta documentación, hay algunos puntos sobre los que nos es imposible precisar y otros que son totalmente oscuros, especialmente el contexto general de este importante hallazgo, ya que no hay ninguna referencia de lo que había en los alrededores de la construcción que pasamos a describir.

Estas excavaciones pusieron de manifiesto la existencia de una estructura rectangular, compuesta por tres muros, de 4,40 ms. de largo por 3,80 de ancho, que en su flanco Norte no estaba cerrada, sino que presentaba una superficie de mortero que se adentraba en el corte, de forma rectangular, y que Llorca interpreta como la entrada al mausoleo. La superficie que delimitaban estos muros era de ladrillos enlucidos, y por debajo aparecía mortero, de dos tipos diferentes, que subdividían el dintorno en dos cuadros (fig. 2, 1). Sobre esta cubierta o solado
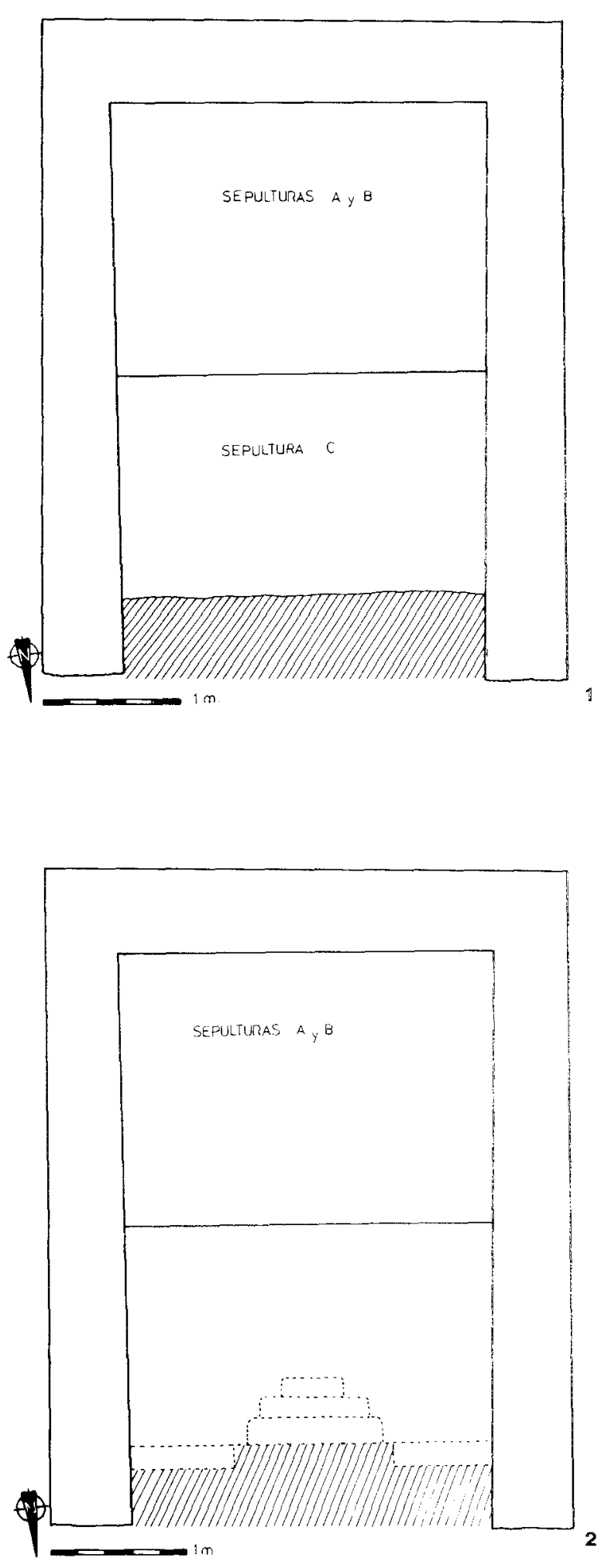

Fig. 2.-Mausoleo del «Camí del Molí dels Frares». 1: Planta, según Llorca. 2: Reconstrucción de la fase inicial. 

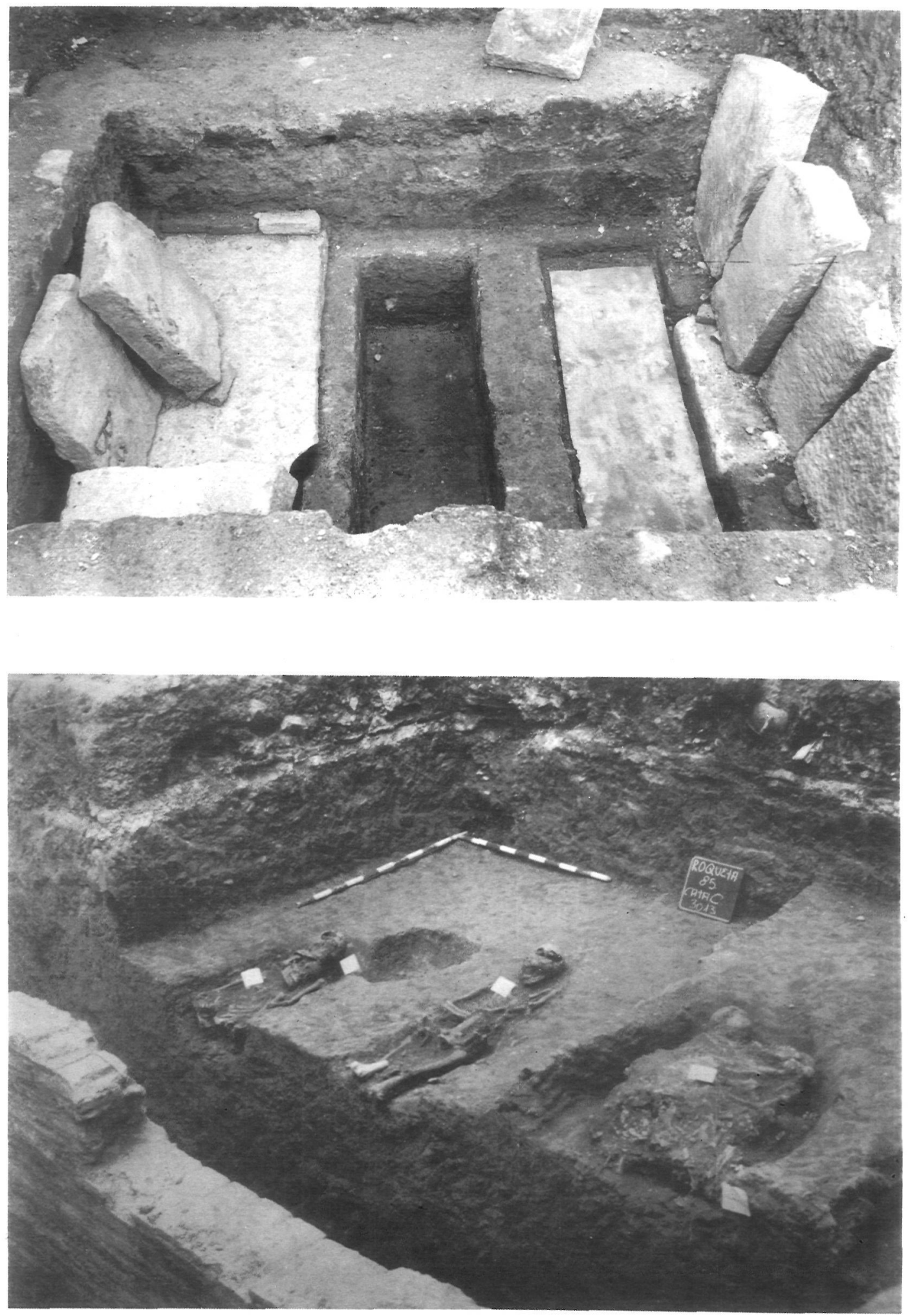

Lám. I._1: Interior del mausoleo del «Camí del Molí dels Frares». 2: Sepulturas de Sant Vicent de la Roqueta. Cata C. 

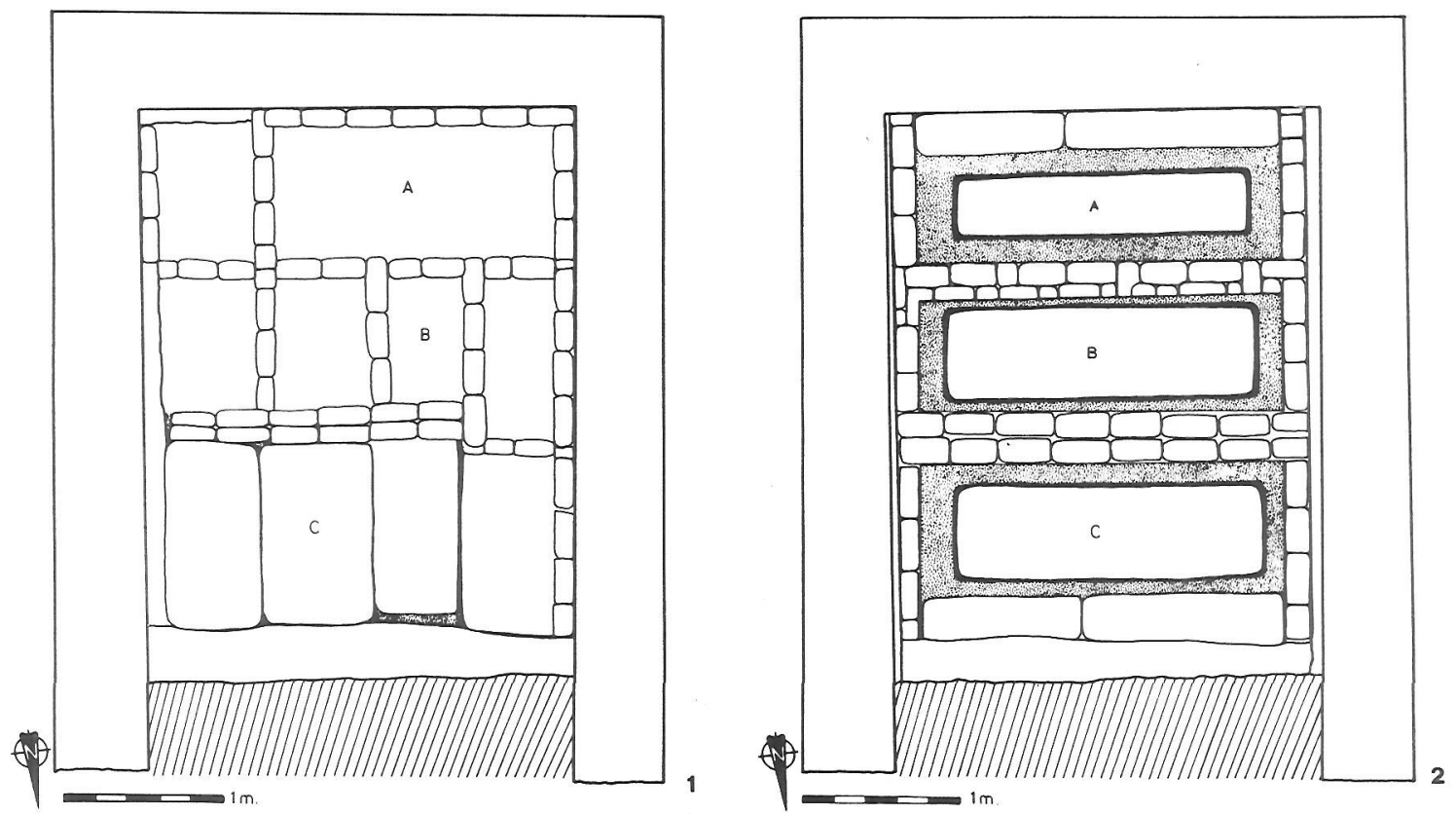

Fig. 3.-Mausoleo del «Camí del Molí dels Frares». Planta. 1: Después de levantar la capa de mortero. 2: Situación de los sarcófagos.

se encontraron restos de osamentas humanas, lo que hizo pensar a Llorca que el mausoleo tenía dos plantas, de las que únicamente se conservaba la inferior. Ésta, cubierta de mortero, tenía en la zona Sur 75 cms. de grosor y en la Norte 65, y eran de distinta factura, ya que en el sector Sur el mortero era de buena calidad, contrastando notablemente con el de la zona Norte, en la que tan sólo los últimos $20 \mathrm{cms}$. eran de mortero y el resto de piedras y tierra. El solado de la zona Norte medía 1,88 ms. de Norte a Sur, por 2,60 ms. de Oeste a Este; el de la zona Sur, 1,95 ms. de Norte a Sur, por 2,65 ms. de Oeste a Este. Se advirtió una juntura en las dos diferentes cubiertas, estando la cara Norte de la zona Sur enlucida, hecho éste que venía a avalar la idea de que había dos momentos de inhumación.

Por debajo de la cobertura de mortero aparecían tres hiladas de losas de piedra de mediano tamaño, la primera de dos losas y la segunda y la tercera de cuatro (fig. 3,1). Bordeándolas y por las juntas había ladrillos. Una vez alzadas estas losas, se puso de manifiesto la existencia de tres huesas rectangulares delimitadas por muretes de mortero, con la parte superior de ladrillo, en el centro, y de grandes losas en los extremos. Tres ataúdes de plomo con tapadera estaban dentro de las fosas (fig. 3, 2); el espacio entre los sarcófagos y la huesa estaba relleno de tierra endurecida y algunos restos de ladri- llos. Llorca describe los ataúdes como dos planchas de plomo unidas, bastante deformadas. El 1A, situado al Sur, mide $1,89 \mathrm{cms}$. de largo por $48 \mathrm{cms}$. de ancho y 52 de alto. El 2A, situado en el centro, fue el que extrajo la pala excavadora, destozándolo, por lo que no poseemos las medidas exactas. Llorca nos indica que sus medidas aproximadas serían $1,90 \mathrm{cms}$. de largo por $55 \mathrm{cms}$. de ancho y 50 de alto. E1 3B, situado en la zona Norte, tenía 1,95 cms. de largo por $55 \mathrm{cms}$. de ancho y 50 de alto. No ostentaba ningún tipo de decoración.

No tenemos referencias precisas de a qué profundidad aparecieron los enterramientos; el único dato que nos facilita Llorca a este respecto es que se encontraban a $1,80 \mathrm{~ms}$. del nivel de la calle. Otro dato problemático es el de la alzada de los muros que limitan el recinto funerario, ya que su excavador no se muestra preciso a la hora de aclarar este punto, puesto que nos indica dos medidas diferentes, a lo que hay que añadir el que no nos da referencias de a qué altura coge las medidas. En la reconstrucción que hemos realizado, basándonos en su diario y sus bocetos, les hemos atribuido a los muros una altura de 1,20 ms., altura esta que aparece en una ocasión (fig. 4).

En el transcurso de la excavación de la tumba 3B se descubrió la existencia de un vano interior de $1,05 \mathrm{~ms}$. de ancho, que serviría de acceso para veri- 

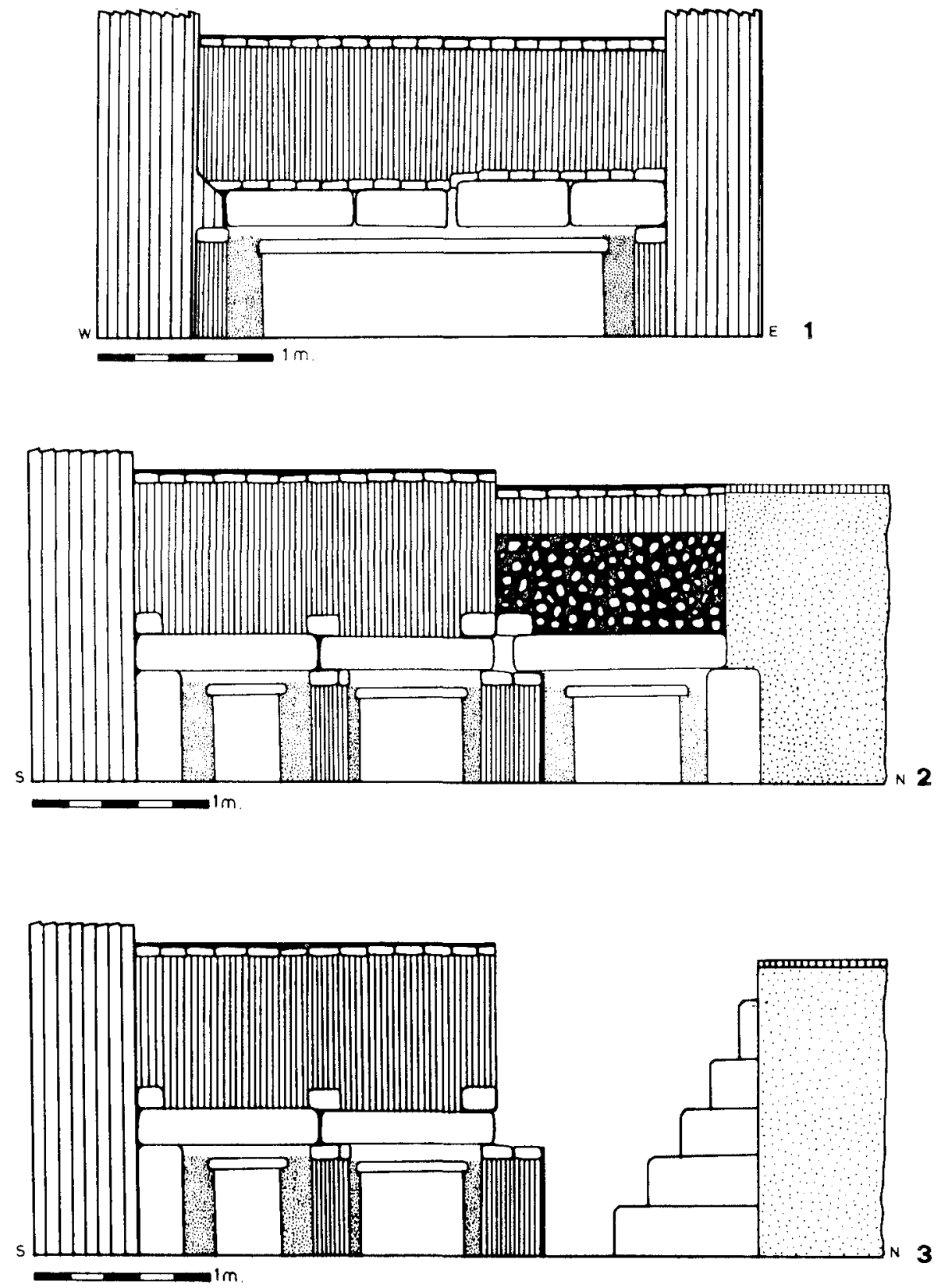

Fig. 4.-Mausoleo del «Camí del Molí dels Frares». Secciones. 1: Este-Oeste. 2: Norte-Sur. Fase final.

ficar, en su momento, el enterramiento que restaba. Unas huellas de posibles peldaños de mortero, cortados y enlucidos, nos confirman tal suposición (fig. 2, 2; fig. 4, 3).

En cuanto al material que acompañaba a las tumbas era escaso. Se encontró una moneda de tamaño grande encima del sarcófago $3 \mathrm{~B}$, de la que Llorca no nos da más referencias y que no ha llegado hasta nosotros. Dentro de la caja 2B, la que des- trozó la pala, se halló, según descripción de Llorca, «un vaso de vidrio verdoso, un anforisca de cuello largo con boca solapada y bordes moldurados, dos asas ciriliformes y base hundida»; tampoco han llegado hasta nosotros ni tenemos fotos ni dibujos. La tumba $1 \mathrm{~A}$ presentaba en su interior cuatro pulseras de azabache de color negro pulimentadas. La n. ${ }^{\circ} 1$ (fig. 5,1 ) es de forma ovalada, con molduras y sección rectangular, decorada con una banda de 

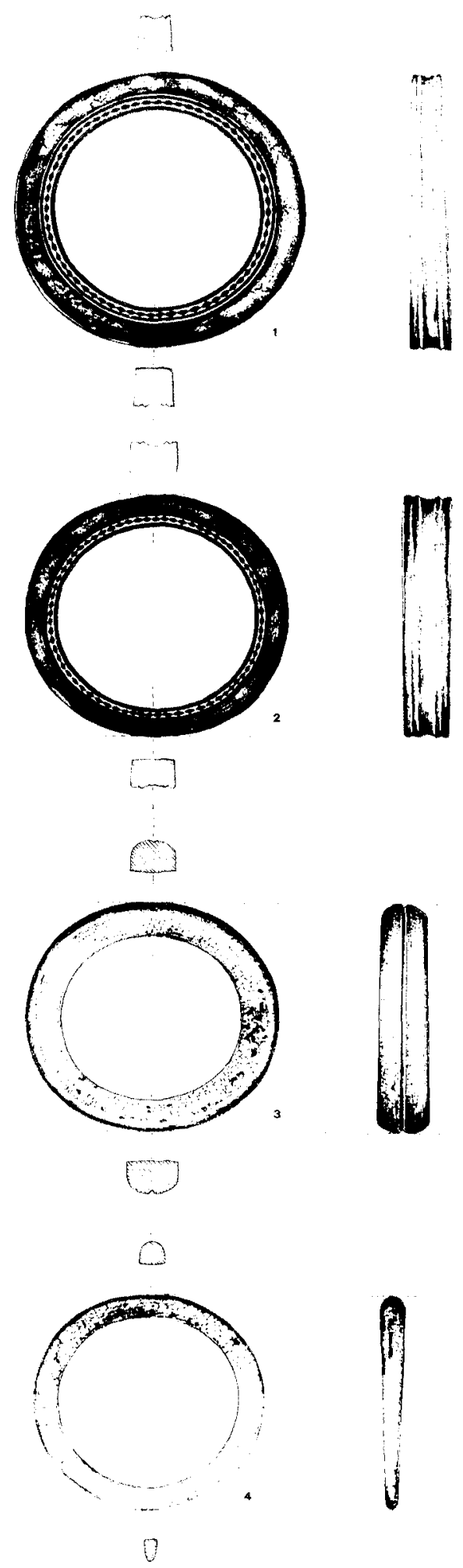

Fig. 5.-Mausoleo del «Camí del Molí dels Frares». Ajuar de la sepultura A. Brazaletes de azabache. incisiones en forma de rombos y una línea circular incisa. Presenta dos agujeritos redondos en la cara interna y frente a éstos otro agujerito. Grosor: 1,2 cms.; anchura: $1,1 \mathrm{cms}$.; diámetro máximo: $8,9 \mathrm{cms}$. La n. ${ }^{\circ} 2$ (fig. 5,2 ) presenta forma ovalada con molduras y sección rectangular; decorada con una banda de inciciones en forma de rombos y una línea circular incisa. Presenta dos agujeritos redondos en la cara interna y frente a éstos otro agujerito. Grosor: 1,5 cms.; anchura: 0,9 cms.; diámetro máximo: 8 cms. La n. ${ }^{\circ} 3$ (fig. 5,3 ) tiene forma ovalada y sección rectangular, y presenta una única moldura que divide la pulsera en dos cuerpos. Grosor: $1,4 \mathrm{cms}$.; anchura: $0,9 \mathrm{cms}$; diámetro máximo: $7,1 \mathrm{cms}$. La n. ${ }^{\circ} 4$ (fig. 5,4 ) es de forma redondeada; se encuentra bastante astillada, lo que le confiere un grosor irregular; no presenta decoración. Grosor medio: 0,5 cms.; anchura: 0,6 cms.; diámetro máximo: $6,9 \mathrm{cms}$.

No sabemos para qué servirían los tres agujeritos redondeados que presentan los ejemplares números 1 y 2 , puesto que no hemos encontrado pulseras que los tengan. Por otra parte, el tipo de decoración que ostentan no aparece reflejado en la bibliografía existente sobre adornos hallados en contextos paleocristianos peninsulares. El motivo de los rombos o puntos se repite en el fragmento de pulsera de la villa romana de la Olmeda (CORTÉS y PALOL, 1974, 108). Sus excavadores comparan esta pieza con el tipo denominado «secteur-porte» por Lepage (1971); aunque éste le atribuye una cronología de finales del siglo III-IV, hay que tener en cuenta que se basa en piezas de oro para su datación. Cortés y Palol piensan en una imitación hiapánica de fines del siglo IV o inicios del V, datación esta que les encaja perfectamente con el resto de la villa. Con las debidas reservas, se podría aplicar a nuestros brazaletes la misma cronología, es decir, finales del siglo IV d. C.

Según las descripciones de Llorca, en las que nos hemos tenido que basar íntegramente para reconstruir el monumento funerario, nos encontramos ante un mausoleo de planta rectangular, probablemente de dos pisos, de los que sólo se conservaba el inferior, que albergaba tres ataúdes de plomo. Queda demostrado, por otra parte, que tendría dos momentos de inhumación y que, probablemente, albergaba una unidad familiar, carácter este que le atribuye Palol $(1967,279)$ a este tipo de monumentos.

Sin embargo, dado lo parco de nuestras informaciones y el hecho de no excavarse alrededor del monumento, quedan en el aire varios puntos que 
consideramos claves, dos de ellos de índole constructiva. En primer lugar, la forma en que cerraría el mausoleo por su zona Norte y, en segundo, cómo sería su cubierta. Los diversos paralelos que presenta este tipo de monumentos funerarios tardorromanos tienen el recinto delimitado por cuatro muros, de lo que parece desprenderse que el muro que delimitaba el mausoleo de Orriols por el Norte se adentraba en el corte. Llorca no amplió la excavación para ver cómo cerraba el edificio, lo que planta dudas respecto a si albergaba o no mayor número de tumbas.

Más problamático se presenta el intuir qué tipo de cubierta presentaría. Del Amo $(1979,187)$, en su estudio sobre la necrópolis de San Fructuoso (Tarragona), nos indica que podrían no estar cubiertos, basándose en los paralelos que presentan los mausoleos aparecidos en una necrópolis paleocristiana de Tiro. Sanmartín Moro y Palol $(1972,452)$ señalan que en la necrópolis de Cartagena este tipo de mausoleo estaba cubierto con bóveda de cañón. También es factible pensar en un techado de tégulas de doble vertiente. En el mausoleo de l'Albir (Alfaç del Pí, Alicante), los muros aparecen reforzados con contrafuertes (MOROTE, 1986, 59).

Otro punto que queda sin respuesta es el de si formaba o no parte de una necrópolis o bien era una sepultura aislada; sólo nuevas excavaciones en la zona podrían aclarar este aspecto. Dada la importancia de este yacimiento, toda el área circundante ha sido considerada como zona de protección arqueológica dentro del nuevo Plan de Ordenación Urbana de Valencia.

Cabe preguntarse, con todo, a qué responde la ubicación del mausoleo. Sabemos que las necrópolis tardorromanas hispánicas se situaban siempre a las afueras de las ciudades, al pie de los caminos rurales, continuando viejos cementerios paganos, o alrededor de templos martiriales o basílicas (PALOL, 1967, 276). Pero nuestro caso, como exponíamos arriba, no podemos aún relacionarlo ni con una necrópolis ni con un monumento aislado, situado, probablemente, al lado de la Vía Augusta, pero lejos de la Valentia, y no tenemos ninguna base para pensar que sea continuación de ningún cementerio pagano ni de haber «martirium» o basílicas por la zona. De todo lo expuesto anteriormente, parece desprenderse el hecho de encontrarnos ante un enterramiento de una unidad familiar perteneciente a alguna villa romana de las cercanías; no tenemos constancia de la existencia de ningún asentamiento rural por esa zona, pero hay que tener en cuenta que actualmente es una exploración hortícola donde la tierra está muy remodelada y cultivada de naranjos, por lo que se hacen difíciles tanto los hallazgos como la prospección en sí. Además, al tratarse de una zona de carácter aluvial, no sería extraño que los restos de época romana aparezcan a casi dos metros de profundidad, como ocurre con esta construcción.

Por otra parte, hay que hacer notar la parquedad de la bibliografía en cuanto a enterramientos pertenecientes a pequeñas villas. Los mausoleos de Centcelles (Tarragona), Alberca (Murcia), Sinagoga de Sádaba (Huesca) y Vegas de Puebla Nueva (Toledo), sólo por citar los más conocidos, pertenecen sobre todo a grandes villas del siglo IV d. C. (HAUSCHILD, 1982, 72 y ss.; PALOL, 1967, 105).

Este tipo de mausoleos de planta rectangular es frecuente en las necrópolis paleocristianas; sin embargo, no son muy numerosos los excavados en la Península. El más conocido, indudablemente, es uno de la necrópolis de San Fructuoso, a orillas del río Francolí, en Tarragona. Fue excavado en la década de los veinte por Serra Vilaró (1932) y su estudio ha sido puesto al día por Del Amo (1979). Presenta mucha variedad de edificios funerarios, siendo los de planta rectangular los que más abundan. $\mathrm{El}$ que se asemeja más al que es objeto del presente estudio es el número 8, que ya excavara Serra. Se conservaban dos pisos; sin embargo, no hay restos ni del acceso a estas cámaras ni de la cubierta del mismo. La autora sugiere, como comentábamos anteriormente, que no estaría cubierto, siguiendo el modelo de la necrópolis cristiana (siglos IV-V d. C.) de Tiro. En cuanto a la entrada a las cámaras, Del Amo piensa que existiría un tercer piso, en el que estarían las escaleras de acceso a los dos inferiores. Data el mausoleo a mitad del siglo IV.

En la necrópolis de Cartagena (SANMARTÍN MORO y PALOL, 1972) aparecen también dos mausoleos de planta rectangular. El mejor conservado tiene restos de la puerta de acceso, en el muro Norte, y al ser dos de los muros más anchos que los otros se sugiere que tendrían una cubierta de bóveda de cañón. No se pronuncian de forma precisa sobre su cronología; sin embargo, apuntan que se trata de una necrópolis romana tardía de fines del siglo IV o principios del V.

En la Vegueta de Santiponce (Sevilla) se encontró en 1903 una necrópolis cristiana perteneciente a Itálica (GARCÍA Y BELLIDO, 1960, 120). No 
tenemos muchas referencias de ella, pero parece que existían mausoleos de planta rectangular, rodeando al posible «martirium». En Francia, mausoleos de este tipo se encuentran, por ejemplo, en el cementerio de Saint Irenée (Lyón), que Reynaud $(1981,130)$ data en los siglos IV y V d. C., y en Italia son frecuentes en la Cisalpina (REYNAUD, 1986).

Mausoleos de planta rectangular de estas características no aparecen más que en contextos tardorromanos, en necrópolis cristianas. La mayoría se puede situar en torno al siglo IV, fecha esta que hemos visto confirmada por los brazaletes que hemos estudiado más arriba y, como veremos, por los ataúdes de plomo.

Los enterramientos en ataúdes de plomo son relativamente antiguos dentro del mundo romano. Algunos sarcófagos se datan en época de Adriano, en la que los talleres microasiáticos porducen gran cantidad de ataúdes exportados e imitados en Occidente. Aunque la mayoría de los ejemplares que conocemos, sobre todo en Occidente, aparecen en un ambiente cristiano, en modo alguno tiene exclusivamente este carácter (BALIL, 1959, 310).

Avi-Yonah observó que este tipo de enterramientos corresponden a una clase social cuyos medios económicos y aspiraciones requerían algo más lujoso que los modestos sarcófagos de cerámica usados en Oriente, pero que no podían aspirar a los costosos sarcófagos de piedra esculturados (BALIL, 1959, 311).

En Hispania son numerosos los hallazgos de sarcófagos de plomo, algunos de ellos decorados. La lista de hallazgos de tumbas romanas aisladas en cajas de plomo es bastante larga, por lo que únicamente haremos referencia a los que poseen contexto arqueológico.

Bien estudiados se encuentran los ataúdes de plomo de la necrópolis de San Fructuoso, hasta un total de cinco, que Del Amo $(1979,92)$ atribuye al grupo de enterramientos más antiguos del cementerio, proponiendo para su inicio la segunda mitad del siglo III y perdurando hasta el siglo IV. A $500 \mathrm{~ms}$. de esta necrópolis, en las excavaciones de la calle Pere Martell (CORTÉS, 1981, 129) han aparecido también dos cajas de plomo que quizá se puedan englobar en esta necrópolis.

Otro conjunto, si no tan bien estudiado, sí representativo, lo componen los ataúdes de plomo de la necrópolis cristiana de Itálica. Son 16 los ejemplares enumerados por García y Bellido $(1960,123)$, de los que ocho contaban con tapaderas decoradas, quedando el resto de la caja sin decorar. No se indica su fechación, únicamente que forman parte de una necrópolis cristiana.

En Córdoba, probablemente procedentes del cementerio paleocristiano, aún sin excavar, se han encontrado también algunos ejemplares con las tapaderas decoradas con franjas.

Saliendo de los contextos de grandes necrópolis, tenemos en Vilasar del Mar (Barcelona) los restos de un pequeño cementerio rural en el que en una de las tumbas apareció un ataúd de plomo.

Un hallazgo especialmente interesante para nuestro trabajo es el de Torre Llauder (Mataró, Barcelona). Sin embargo, data de principios de siglo y la información que poseemos es escasa. Se trata de un mausoleo en el que apareció un sarcófago o una urna de plomo, no sabemos si decorado o liso. Se data en el siglo III d. C. (BALIL, 1959, 317).

Tumbas aisladas se han encontrado en Terrassa (Barcelona), Villaricos (Almería), Carteia (Cádiz), Peñaflor y Écija (Sevilla), entre otros.

Como acabamos de ver, los sarcófagos de plomo en el contecto peninsular siempre parecen formar parte de necrópolis cristianas, y la fechación más fiable que poseemos, citada anteriormente, es la propuesta por Del Amo, que los sitúa entre finales del siglo III, para el inicio del modo de enterramiento, perdurando durante todo el siglo IV d. C. En las necrópolis del Sur de Francia y Norte de Italia, las sepulturas de esta clase siempre son las más antiguas de las necrópolis cristianas, fechándose, como en el caso hispánico, entre fines del siglo III y el IV (REYNAUD et alii, 1986).

La forma en que estaban dispuestos estos ataúdes eran diversas. En algunas ocasiones requieren una especial protección, ya sea dentro de un sarcófago de piedra o cerámica o de una caja de mampostería o tégulas. Los que más se asemejan a los de Orriols son los de Itálica, en donde las tumbas estaban delimitadas por muretes de ladrillos, y dentro se colocaba el ataúd, estando cubierto con tégulas, ladrillos o losas. En la necrópolis de Tarragona hay algunos recubiertos con tégulas a doble vertiente. También puede darse el caso de que formen una caja con losas e introduzcan dentro el ataúd. 


\section{SANT VICENT DE LA ROQUETA}

El caso de los restos hallados recientemente (1985) en el convento de Sant Vicent de la Roqueta presenta caracteres bastante diferentes al descrito en Orriols, lógico, por otra parte, si consideramos que este lugar es, presumiblemente, el lugar de culto cristiano más antiguo de Valencia.

Durante la última persecución de Diocleciano (303-305), fue Daciano el encargado de la represión del cristianismo en Hispania (1), llegando a Caesaraugusta, en donde la doctrina cristiana había calado mucho, en el año 304 ó 305. Una vez allí, mandó prender a Valerio (o Valero) el obispo de la diócesis, y al diácono Vicente, mandando que fueran trasladados a Valentia, para que se les juzgase, sin que se sepa a ciencia cierta a qué respondía esta actitud. Bien es verdad que en la ciudad del Turia el auge del cristianismo por entonces debía ser menor. La sentencia fue de destierro para el obispo y de muerte para el joven diácono. No nos vamos a extender aquí sobre los denominados lugares vicentinos de la ciudad, tema que nos parece que ha sido ya brillantemente desarrollado por algunos eruditos locales (CHABÁS, 1904; SANCHIS SIVERA, 1920), sino que nos vamos a ceñir al papel de Sant Vicent de la roqueta en este episodio martirial. El diácono murió tras sufrir todo tipo de torturas y, según la tradición, Daciano mandó arrojar su cuerpo a la playa y, con posterioridad, al mar. A partir de aquí las discrepancias entre los autores son notables. Llobregat $(1977 \mathrm{a}, 10 ; 1977 \mathrm{~b}, 26)$, apoyándose en la descripción que hace Prudencio en su «Peristephanon» de la playa de arribada de la barca que transportaba el cuerpo del mártir, se inclina por algún punto de la costa Sur de Valencia, pronunciándose por la Punta de l'Illa, en Cullera, ya que tanto la toponimia de la zona como algunos hallazgos arqueológicos parecen avalar la idea de un asentamiento paleocristiano en las cercanías.

El resto de los autores, siguiendo la tradición, piensan que fue en el área de la Roqueta donde Daciano mandó depositar el cuerpo del santo. Hemos de tener en cuenta que la Albufera no discurría muy lejos de aquí y, después de diversas incidencias que entran dentro del campo de la hagiografía, fue de-

(1) Agradecemos la colaboración prestada por Rosa Estellés en la elaboración de las figuras 1, 9 y 10 y a Juan Casado por las figuras 5,9 y 11 . finitivamente arrojado el cuerpo al mar, de donde el agua lo devolvió a la orilla, muy cerca del lugar en el que había sido depositado originalmente, y a donde fue trasladado después de la paz de la Iglesia (313). Siguiendo la costumbre muy extendida a partir de estos momentos, sobre su tumba se levantaría una pequeña iglesia que posteriormente, debido al auge que experimentó el culto del santo, pararelo al crecimiento del cristianismo valenciano, tuvo que ampliarse. Con el objeto de respetar el primitivo emplazamiento del sepulcro del mártir se cambiaría la orientación de la iglesia, situando el ábside junto a la Vía Augusta, que discurriría por la actual calle de San Vicente Mártir; un hecho análogo sucedería con la iglesia de San Pablo, en Roma (CASTELL, 1973, 11). Uno de los argumentos que pudieran avalar que la tumba del mártir se situó en el templo de Sant Vicent de la Roqueta es la procedencia del sarcófago de mármol blanco, actualmente depositado en el Museo de Bellas Artes de Valencia. Es esta una opinión cada vez más compartida por los estudiosos del tema. La fuerza de este argumento reside en las características del sarcófago; Sotomayor $(1975,207)$ lo sitúa en la segunda mitad del siglo IV y por su calidad lo cree originario de algún taller italiano. Martínez Aloy (s./a.) se pregunta la identidad del personaje a quien pudiera corresponder un sarcófago de tanta calidad, importado, y en una fecha tan temprana. En cualquier caso, se trataría de un importante personaje cristiano del siglo IV. Esto encajaría con la personalidad de un mártir como Sant Vicent. Sin embargo, aunque existe una gran probabilidad, no hay argumentos definitivos ni pruebas concluyentes para atribuir el citado sarcófago ni al templo de Sant Vicent de la Roqueta ni a su utilización como la sepultura de Sant Vicent. Esta es la postura de, entre otros, Llobregat $(1977 \mathrm{~b}, 18)$.

Tras la invasión musulmana, el paradero de las reliquias del santo es incierto. Son numerosas las crónicas que narran el traslado de los restos del mártir a un lugar lejano. La más extendida de ellas es la que relata el moro Rasis, escrita casi dos siglos después de acaecidos los hechos que describe. Para este autor el cuerpo del santo fue sacado de Valencia y trasladado a Portugal, al promontorio Sacro

(2) No entraremos en la discusión, ampliamente tratada por Sanchis Sivera (1920), sobre la fecha en la que se encontraban Daciano en la Península ni el cargo que ocupaba. 
(hoy denominado cabo de San Vicente), donde se le edificó una iglesia. Con posterioridad, sus restos fueron llevados a Lisboa. La crónica de Aymón se refiere a Castres (Francia) como lugar al que fue trasladado el santo.

Chabás $(1909,73)$ pensaba que las reliquias del mártir no fueron sacadas de Valencia, sino ocultas en algún sitio seguro. Castell $(1973 b, 17)$ cree que a raíz de la inestabilidad política acaecida con la caída del Califato de Córdoba, en los comienzos del siglo XI, las reliquias debieron de esconderse o bien dentro de la basílica o en sus alrededores. Esta oponión queda avalada por la peregrinación que a Tierra Santa realizara, a principios del siglo XII, Teudovildo, obispo de la diócesis valentina, quien, durante su estancia en Bari (Italia), se sintió gravemente enfermo y entregó el brazo del mártir al arzobispo de la ciudad, Elías, con el encargo de colocarlo en la catedral de San Nicolás, si él moría. Este hecho revela, según Sanchis Sivera $(1920,304)$, que en la ciudad de Valencia quedarían reliquias del santo, ya que no concibe el autor que no conservara ninguna. Por otra parte, el ocultamiento de cuerpos de santos o mártires era frecuente en aquella época. $\mathrm{Re}-$ cientemente se ha considerado que este episodio de Teudovildo podría no ser cierto, dado que hay indicios de duda sobre la autenticidad de la única fuente que habla de este episodio. Se trataría, entonces, de un hecho ficticio para realzar o justificar la presencia de estas reliquias en Bari (EPLAZA y LLOBREGAT, 1982, 22 y 24).

En lo que respecta a la historia del monasterio de la Roqueta, parece que ésta transcurre paralela a la de la iglesia. Aunque no existen datos fehacientes sobre su fecha de fundación, la famosa inscripción del obispo Justiniano data del siglo VI y en ella parece confirmarse la existencia de un monasterio del que era abad el mismo Justiniano, dedicado a San Vicente. Este convento es identificado por muchos estudiosos con el de la Roqueta. No obstante, algunos eruditos sitúan el convento en otros lugares (LLOBREGAT, 1977a). El reciente artículo de A. García (1983, 114 ss.) viene a confirmar, basándose en documentos medievales, la existencia de unos «fratres» al servicio del culto de San Vicente todavía en el siglo XII, que debieron abandonar Valencia debido a la presión almorávide. Queda claro que durante el dominio musulmán no se crearían nuevos monasterios en la ciudad, por lo que éste debía de rastrearse desde época anterior, y es aquí donde el epitafio de Justiniano cobra todo su valor.
Pese a todo, no existía constancia arqueológica que afirmara o negara lo que acabamos de comentar, por lo que cuando al SIAM se le ofreció la oportunidad de realizar excavaciones en el convento de la Roqueta se pensó que con ellas se solucionarían muchos de los problamas planteados.

Las excavaciones se iniciaron en julio de 1985 y terminaron en enero de 1986 y pretendían poner de manifiesto tanto los restos medievales como paleocristianos. Para ello, en un principio, se efectuaron tres catas, una a cada lado de la portada románica que comunicaba el convento con la iglesia y que tiene los capiteles decorados con motivos sacados del martirio de Sant Vicent, y la tercera en el jardín del claustro. Las tres catas pusieron de manifiesto la existencia de varios niveles medievales cristianos que aún se encuentran por estudiar (fig. 6).

La cata $\mathrm{B}$, al igual que la $\mathrm{A}$, presentaba un osario con gran número de restos humanos revueltos. La fechación de esta deposición, con toda seguridad, se puede situar entre los siglos XIV-XV, aunque entre los objetos que aparecieron acompañando a la gran masa de huesos tenemos que citar dos vasijas de vidrio cuyas formas se relacionan con las 111 y 133 de la clasificación de Isings (1975), que éste data en el siglo IV d. C. Pero estudios recientes en Marsella parecen indicar que los inicios de la forma Isings 111 han de llevarse a la segunda mitad del siglo $\mathrm{V} \mathrm{d}$. C., siendo común su presencia en niveles de los siglos VI y VII (FOY y BONIFAY, 1984, 303-304). En el País Valenciano, este tipo de copa lo tenemos representado en Lucentum, en donde se le atribuye una cronología de los siglos V y VI d. C. (SÁNCHEZ DE PRADO, 1984a, 96). De Valentia conocemos otra pieza de la forma Isings 133, casi idéntica a la de la Roqueta, procedente de la iglesia de Sant Bertomeu (SÁNCHEZ DE PRADO, 1984b 40). Esto nos hace suponer que nos encontramos ante unos enterramientos que probablemente fueron vaciados de dentro de la iglesia o de sus alrededores y posteriormente depositados en un fosar al pie de la portada (fig. 9, 1 y 3).

En la cata $C$, en el centro del patio del claustro, aparecieron tres enterramientos, de los que no se pudo concretar su datación al carecer de datos en que basarse. No obstante, algunos leves indicios nos hacen presuponer que no sería extraña su adscripción a la época romana tardía. Los enterramientos estaban en tres fosas paralelas excavadas en una capa natural de arcilla, a un metro de profundidad. Los esqueletos estaban orientados de Oeste a Este. 


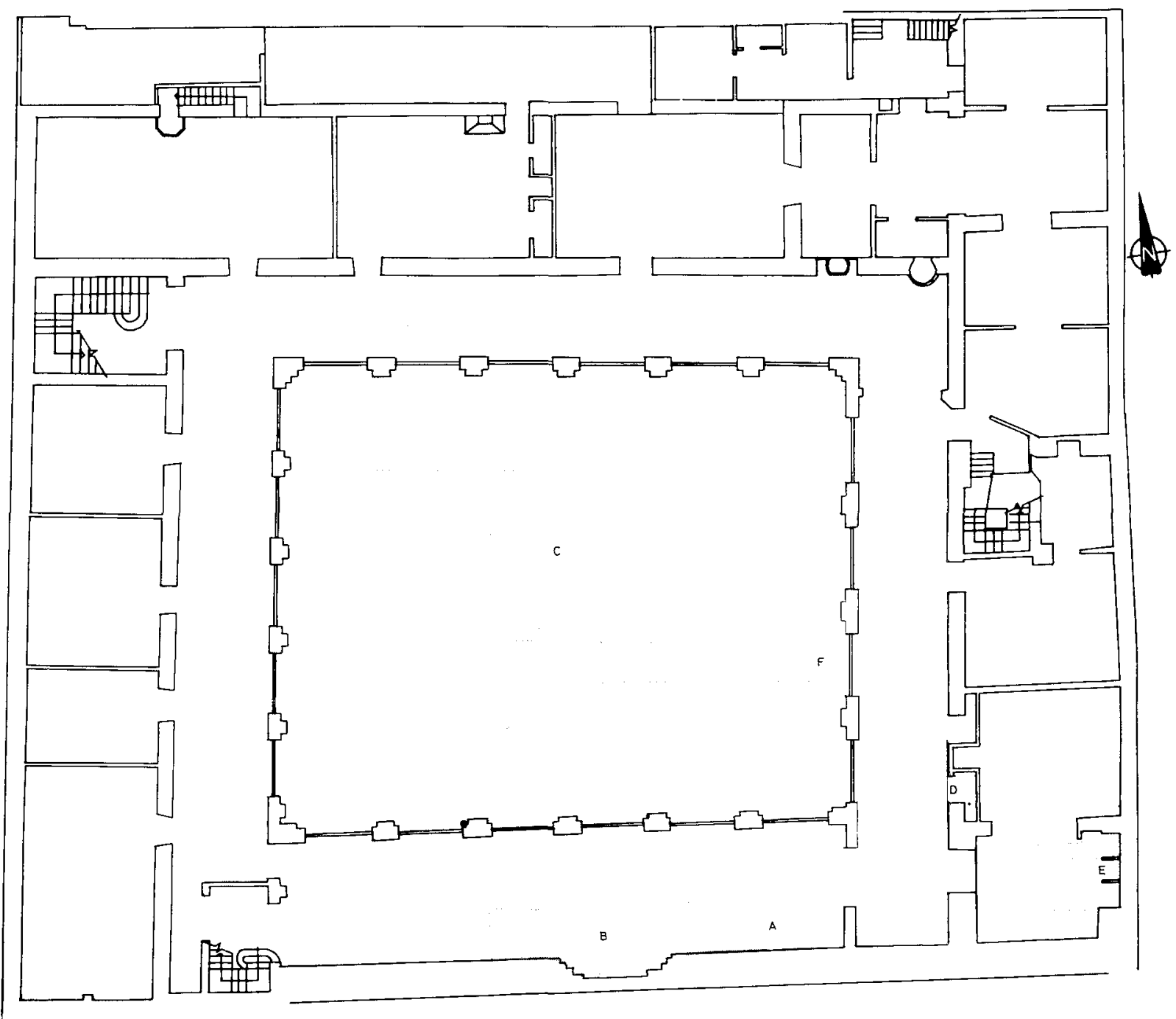

Fig. 6. - Sant Vicent de la Roqueta. Plano de las excavaciones (1985-86).

La fosa situada más hacia el Sur presentaba una doble inhumación y uno de sus componentes conservaba puesto un anillo de bronce. La sepultura central era individual y la septentrional apareció revuelta, dando la impresión de ser un pequeño osario con los restos de varios individuos. Las tres fosas estaban encaladas y se apreciaba bastante cuidado en su ejecución. Lo mismo se observó en la deposición de los cuerpos de las dos primeras fosas, que, como hemos visto, estaban orientadas de Oeste a Este. Esta disposición, el hecho de que se asentaran sobre tierra virgen, rasgo este que no se da en las abundantes sepulturas medievales, y que sus pies fueran cortados por una constucción de datación bajomedieval, es lo que nos induce a pensar en su adscrip- ción a un momento pre-islámico, ya que indudablemente su orientación no es la típica de los enterramientos musulmanes. Además, la tipología del anillo, único elemento arqueológico aparecido dentro de las fosas, es similar a un ejemplar procedente de un enterramiento de la calle del Mar, que veremos más adelante (lám. I, 2; fig. 9, 2).

La cuarta cata (D) se realizó en el pasillo Oeste del claustro, y medía $3 \times 2 \mathrm{~ms}$. En sus niveles iniciales seguía la pauta de las otras tres catas. A una profundidad media de dos metros apareció un estrato de tierra arcillosa de color rojizo, similar a la que había en las tres primeras catas y que, como hemos visto, era donde estaban excavados los enterramientos de la cata C. A 2,40 ms., aproximadamen- 

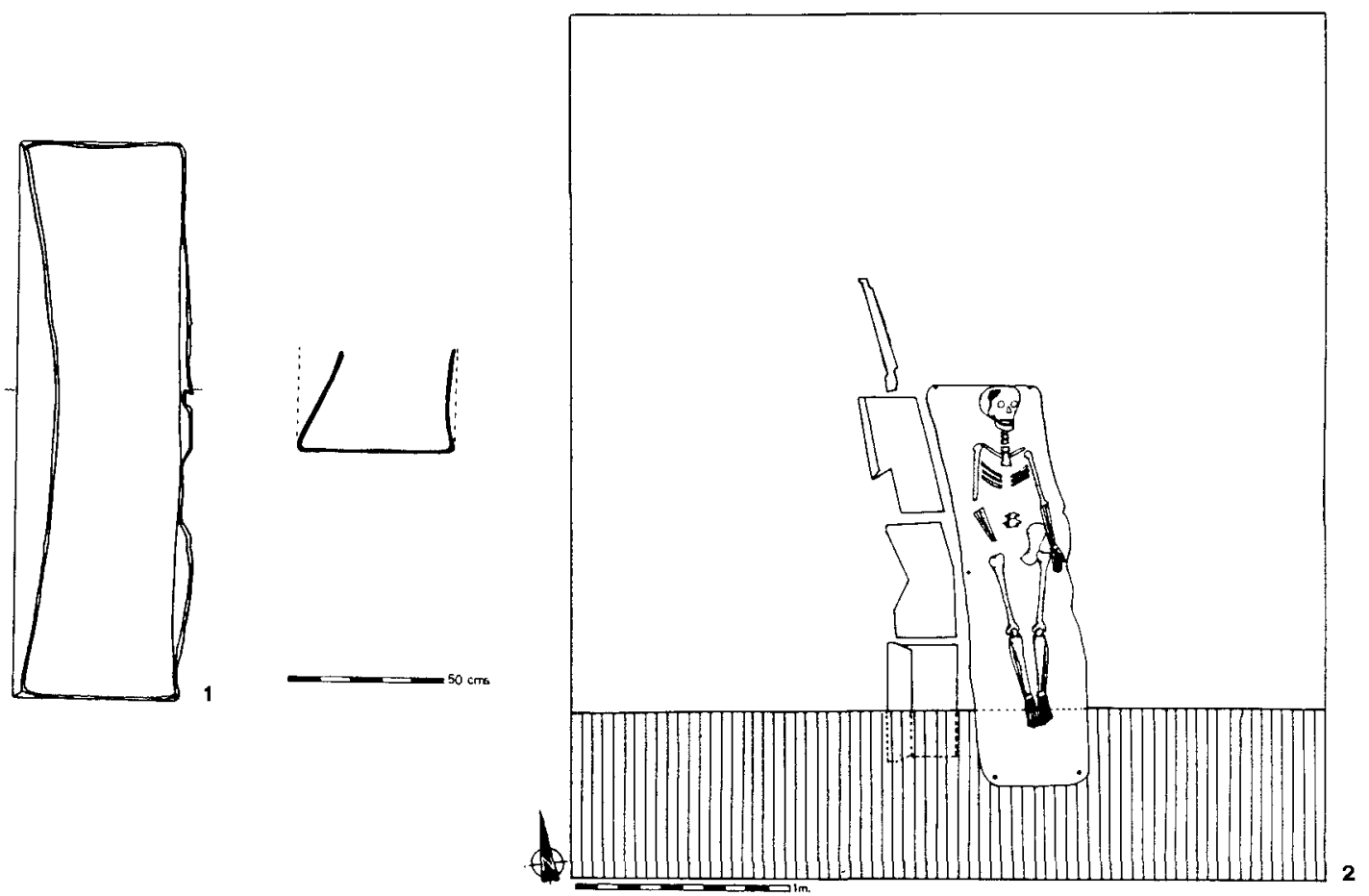

Fig.7.- Sant Vicent de la Roqueta. 1: Planta y sección del sarcófago de plomo. 2: Planta de la cata D.

te, empezaron a aparecer tégulas de gran tamaño en posición vertical, que se adentraban tanto en el corte Sur como en el Oeste. A tres metros se encontraba un ataúd de plomo sin tapa y cubierto de tierra, que se adentraba en el corte Sur, por lo que se decidió ampliar la cata por los costados, un metro en dirección Sur y medio metro hacia el Oeste (fig. $7,2)$. La caja de plomo se encontró deformada con uno de sus lados abollado (fig. 7, 1). Mide 1,90 ms. de largo, $51 \mathrm{cms}$. de ancho y $31 \mathrm{cms}$. de alto. El grosor es de $0,5 \mathrm{cms}$. y tiene en el fondo seis pequeños orificios redondos, de los que desconocemos su función. El esqueleto que albergaba no estaba en buen estado de conservación, ya que se encontraba aplastado por el peso de la tierra que había entrado en el ataúd, al carecer éste de tapa. Las tégulas que se hallaban al lado del sarcófago, de $52 \mathrm{cms}$. de largo, 40 de ancho y 3 de grosor, debieron de desempeñar el papel de cubierta formando doble vertiente (lám. II). Por la situación en que se hallaron, daban la sensación de haber sido ladeadas y la tumba violada, ya en la época que se efectuó el enterramiento, puesto que no aparecen intrusiones estratigráficas (fig. 8). Tal vez por ello, la tumba no tenía ningún tipo de ajuar, ni tan siquiera algún fragmento de ce- rámica, ni dentro de la sepultura ni en sus alrededores.

Los enterramientos en ataúdes de plomo suelen tener tapaderas del mismo metal, aunque por encima se los cubra con tégulas o losas, como hemos visto en el mausoleo de Orriols. Ataúdes de plomo con cubierta de tégulas a doble vertiente aparecen en las excavaciones del carrer Pere Martell (CORTÉS, 1981, 130), cerca de la necrópolis de San Fructuoso. Basándonos en lo expuesto con anterioridad, podemos datar el enterramiento a finales del siglo III, como fecha temprana, y más verosímilmente en el siglo IV d. C.

El descubrimiento de estas sepulturas, junto a las piezas de vidrio, son, por ahora, los únicos restos arqueológicos que parecen confirmar la tradición en torno a Sant Vicent de la Roqueta. Como las tumbas romanas no suelen aparecer aisladas y era una costumbre el enterrar a los muertos cristianos en los alrededores de las primitivas basílicas y centros martiriales, se realizaron dos nuevas catas para intentar detectar nuevos vestigios de esta época. Sin embargo, ninguna de ellas proporcionó nuevos restos relacionables con la época que tratamos aquí, pero sí con la islámica y bajomedieval. 


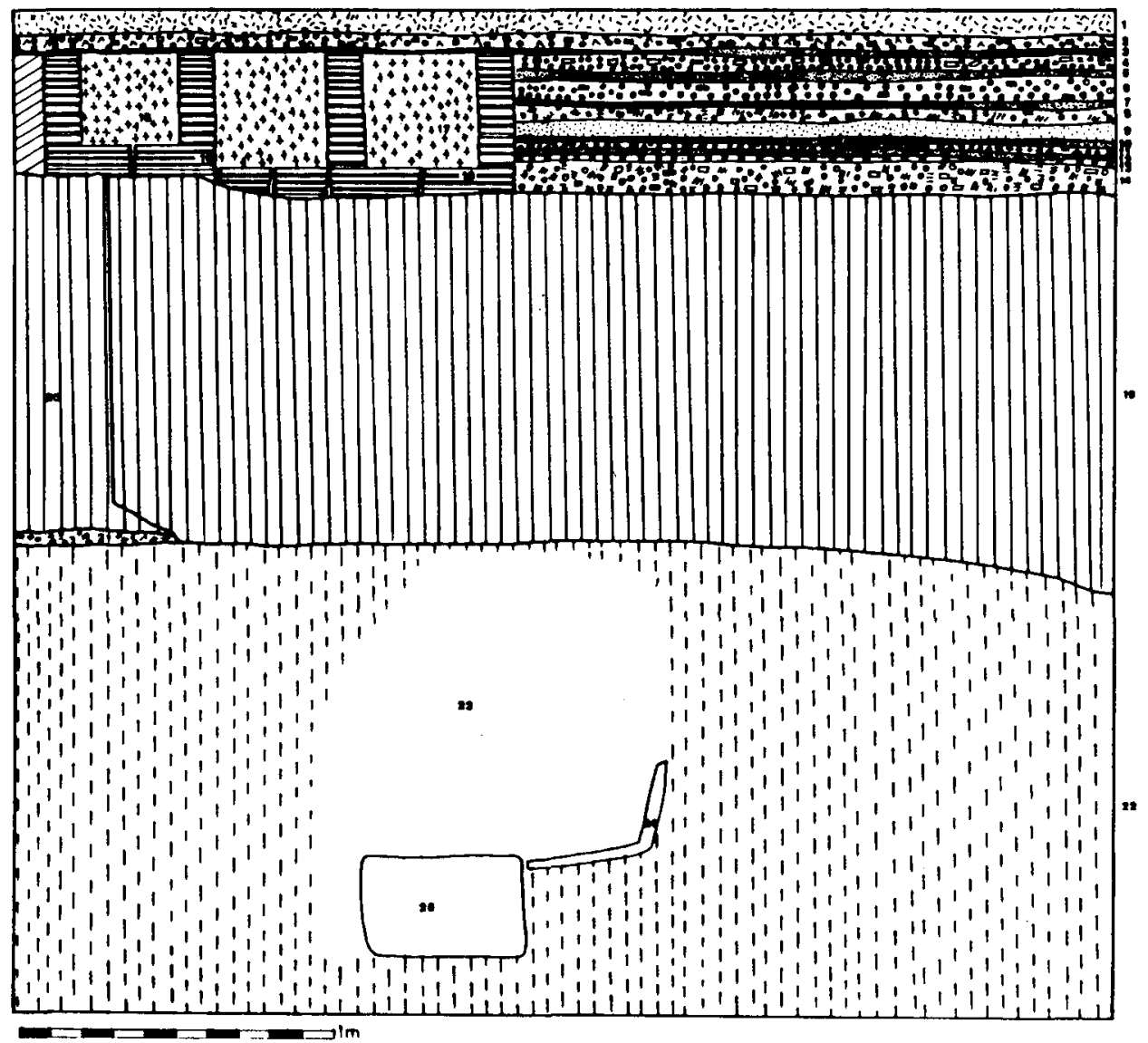

Fig. 8. - Sant Vicent de la Roqueta. Cata D, corte Sur.

Dentro de esta zona sólo se conoce otro hallazgo de posible datación romana, una pequeña figurita de bronce de $6,5 \mathrm{cms}$. de altura, plana por su parte posterior, que representa una cabeza barbada con el pelo enrollado y que se ha interpretado como una posible interpretación de Zeus Siríaco. (GÓMEZ SERRANO, 1941).

Estas excavaciones han servido para poner de relieve que la tradición erudita que apuntaba la existencia de un complejo paleocristiano en la zona de la Roqueta tiene, en principio, un apoyo documental, aunque serán necesarias nuevas excavaciones, que se deberán centrar en el interior de la iglesia, para valorar plenamente su magnitud, especialmente en el aspecto de los posibles restos arquitectónicos basilicales.
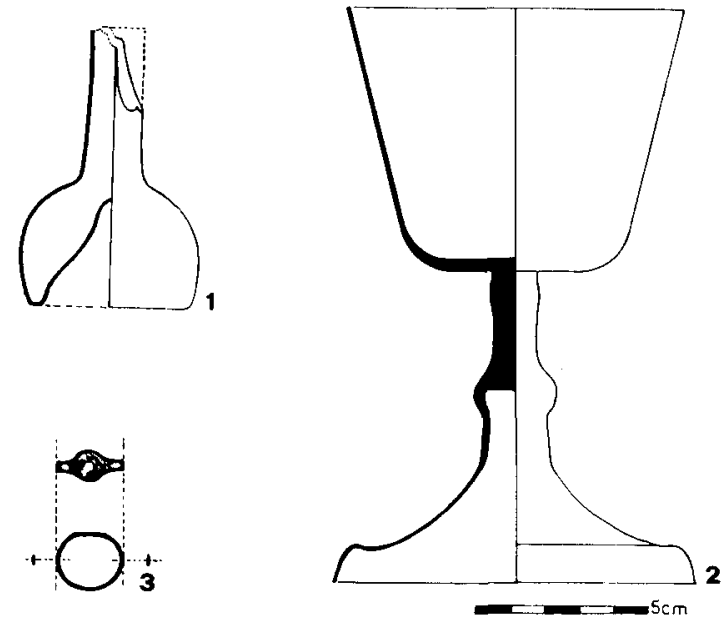

Fig. 9.-Sant Vicent de la Roqueta. 1 y 2: Vasijas de vidrio (cata B). 3: Anillo de bronce (cata C). 

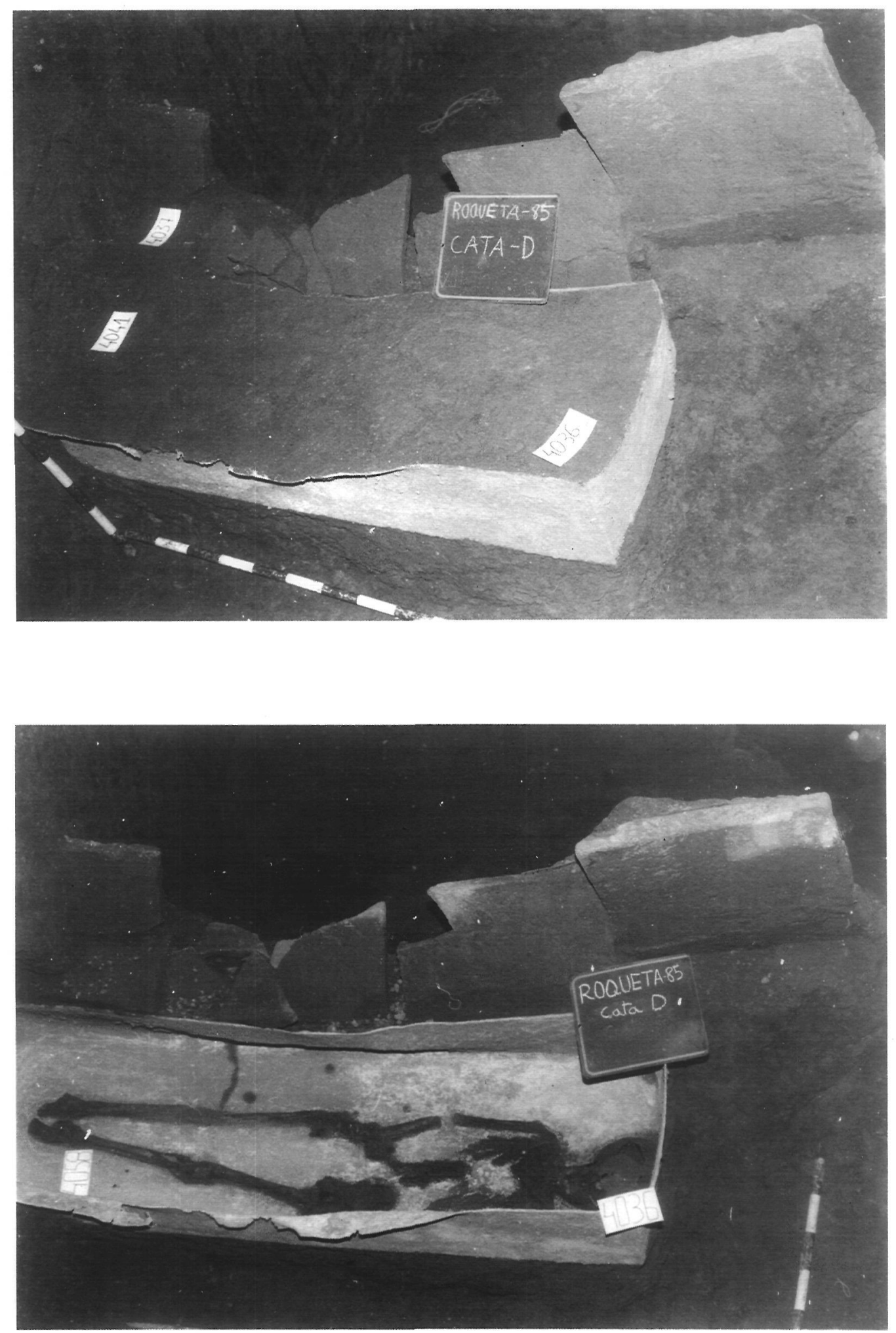

Lám. II.-Sarcófago de plomo de Sant Vicent de la Roqueta. Cata D. 


\section{LA NECRÓPOLIS DE LA CALLE DEL MAR}

Entre 1981 y 1983, el SIAM excavó en un extenso solar de la calle del Mar (fig. 10), y en 1985 también fue objeto de excavaciones un pequeño solar contiguo. La información recogida en ambos fue muy abundante, tanto para la época romana como para la medieval. Especial interés tienen una serie de estructuras y materiales que se datan del siglo III al VII. En esta ocasión vamos a pasar revista a unos enterramientos de época visigoda y a la problemática que plantean por su ubicación dentro de la topografía de Valentia.

En este cementerio se señalaron cuatro enterramientos bien diferenciados: tres eran fosas, más o menos evidentes, y el cuarto era una sepultura colectiva (fig. 11; láms., II y IV, 1) que pasamos a describir en primer lugar. Se encontraba en la parte
Norte del solar (sector F) y se excavó en enero y febrero de 1983. Apareció incompleta, ya que un gran pozo de época islámica la había destrozado en su parte Este y Sur, según se comprobó en posteriores campañas. Lo que quedaba de la estructura original permite suponer que estaba formada por una hilada de grandes losas hincadas verticalmente que se alternaban de modo irregular con algunos sillares de menores dimensiones, en dos hiladas éstos, procedentes todos de construcciones romanas. La altura de estas paredes iba de 1,10 a 1,40 ms., según las zonas, y el grosor variaba de 30 a $40 \mathrm{cms}$. El conjunto delimitaría una zona posiblemente rectangular (la extensión de los muros conservados era de $2,40 \times 1,50 \mathrm{~ms}$.), dentro de la cual yacían, en bastante desorden, los restos amontonados de once individuos. Con todo, a pesar de la evidente falta de orden de los esqueletos, parece adivinarse que bas-

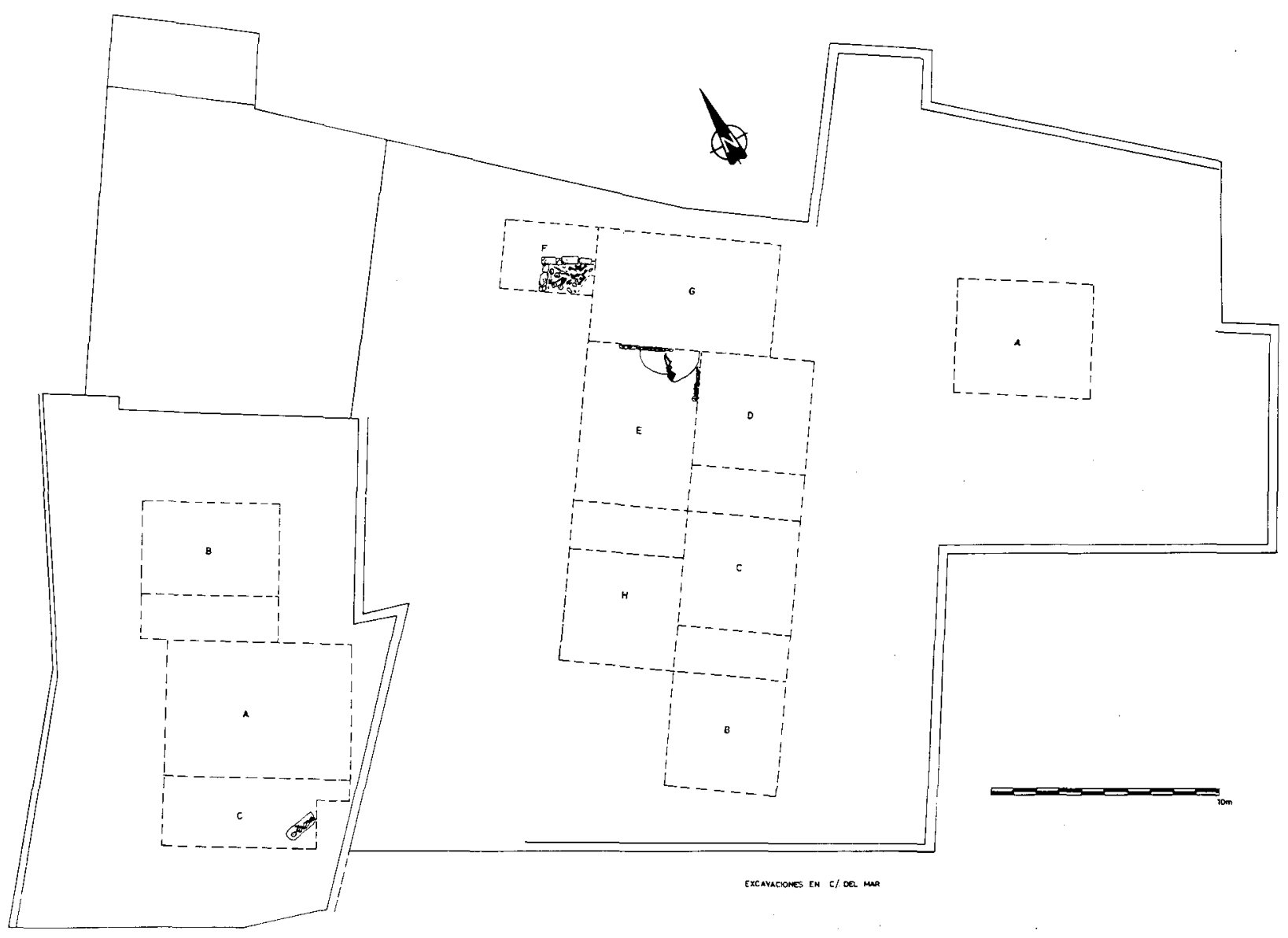

Fig. 10.-Calle del Mar. Plano de las excavaciones (1981-85). 


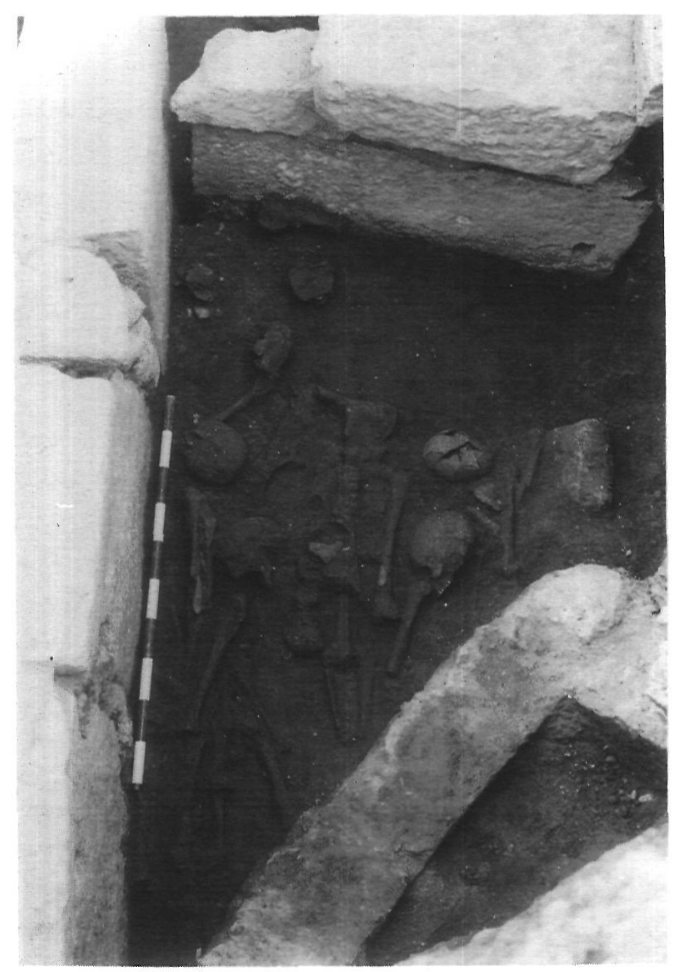

tantes de ellos presentaban cierta tendencia a estar orientados en dirección Este-Oeste, al menos la mayoría de los huesos largos, aunque, insistimos, el aspecto general que presentaban era claramente el de una deposición efectuada con poco cuidado. Este osario llegaba a tener un espesor de un metro, y hasta que un especialista no los examinó con detalle no se pudo averiguar con exactitud el número total de individuos. Dada la gran mezcolanza de los huesos entre sí, no es descartable la posibilidad de estar ante un enterramiento secundario o ante varias deposiciones sucesivas, pero no coetáneas, fenómeno bastante normal en época visigoda, aunque no conocemos casos como éste, con tantos restos humanos juntos.

Las losas que componen esta construcción funeraria estaban trabadas sólo con tierra, dando al conjunto un aspecto bastante tosco y descuidado que se realzaba por la misma irregularidad, en forma y tamaño, de estas piedras. Entre los espacios que había en los amplios intersticios de los sillares sólo se recogieron unos pocos materiales. El más destacable fue un fragmento de clara D de la forma Hayes 52, decorada con un león en relieve aplicado. Entre la espesa capa de huesos humanos apenas se recuperaron materiales arqueológicos, entre los que había unos pocos y pequeños fragmentos sin forma de clara $\mathrm{C}$ y $\mathrm{D}, \mathrm{y}$, como pieza más interesante, un anillo de bronce con un aspa incisa (fig. 9, 3), parecido al que se halló en un enterramiento de Sollana (Valencia), que se ha datado a fines del siglo VI o inicios del VII (FLETCHER y PLA, 1952, f. 10), y al encontrado en la Roqueta.

Sobre las losas verticales que enmarcaban este enterramiento en su parte exterior, se apoyaba una homogénea capa de tierras marrones muy oscuras, en las que se recuperó bastante material cerámico que nos proporciona una buena pista cronológica para intentar fechar esta construcción. La cerámica fina más abundante fue la clara $D$, con unas formas que hay que datar por lo menos a partir de la primera mitad del siglo VI d. C., como la Hay. 99, la más abundante, la Hay. 97 y la Hay. 104 (ATLANTE, 1981, 94-96, 109, 110). Además estaban presentes la Hay. 58, 59 y 91 . Entre las cerámicas comunes abundaban las de procedencia africana y las ollas exvasadas de factura tosca. En menores proporciones se recogieron fragmentos de grandes tinajas con el borde vuelto hacia fuera (tipo 12 de Vegas) y de otras cerámicas de uso utilitario: ta- 
paderas, boles, morteros y jarras. También se recuperaron dos monedas del siglo IV d. C.

Tal vez en su momento dispusiera de algún tipo de cubierta, pero sólo se conservó «in situ» una posible parte de ella, formada simplemente por un fragmento arquitectónico moldurado perteneciente probablemente a la cornisa de un edificio de época imperial. Esta pieza arquitectónica yacía horizontalmente sobre una de las losas verticales que delimitaban la estructura funeraria. El caso evidente es que cuando se realiza la última deposición de cadáveres, la tumba debió quedar sin una tapadera sólida o ésta fue levantada en un momento anterior al siglo X o XI, en el que se data una capa de arcilla rojiza que cubría la sepultura y sus alrededores. Esta construcción se asentaba sobre la tierra virgen, excepto en su parte Oeste, que cortó una pequeña bolsada que se extendía tanto por el interior como al
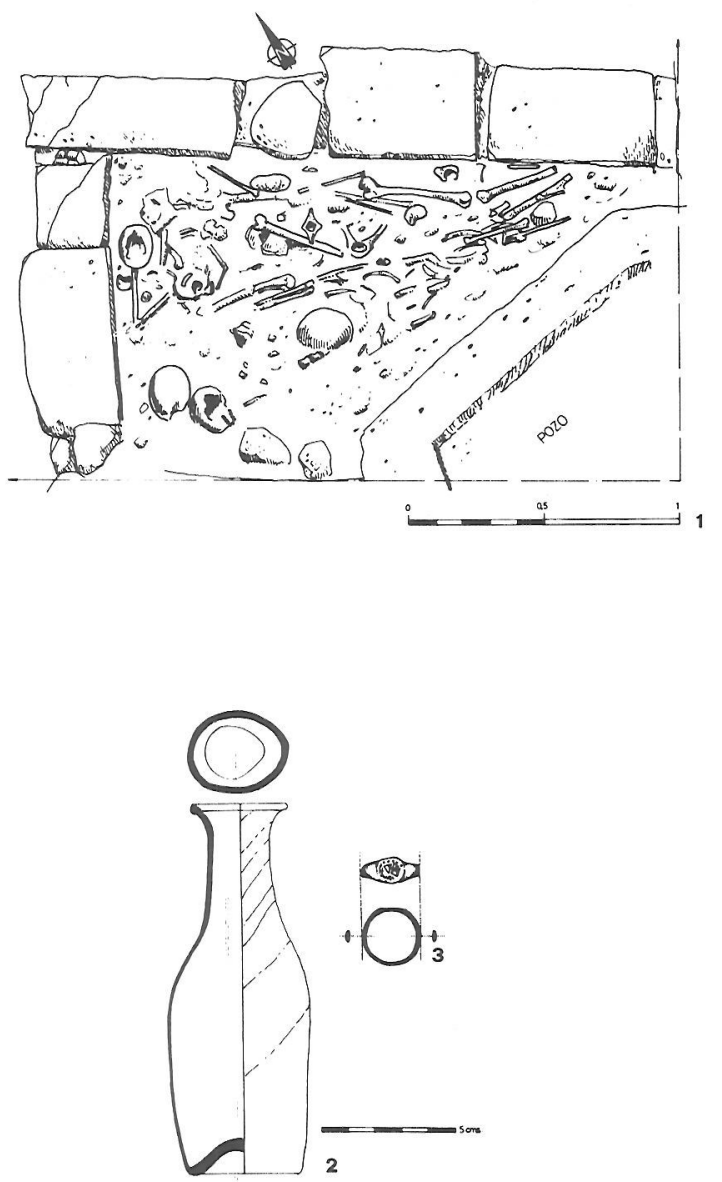

Fig. 11.-Calle del Mar. Sector F. 1: Planta de la sepultura colectiva. 2: Botella de vidrio. 3: Anillo de bronce. exterior de esta estructura funeraria por su lado occidental y cuya datación nos sirve para tener una buena fecha «post quem». El escaso material puede datarse a partir de finales del siglo IV d. C. o inicios del V d. C., gracias a unos pocos fragmentos de clara D de la forma Hay. 91 (HAYES, 1977). La pieza más completa fue una botella de vidrio con cuello de embudo y cuerpo cilíndrico, que se puede datar a partir del siglo III y con más seguridad en el siglo IV d. C. Se asemeja algo a la forma 102d de Isings (1975) (3). A través del estudio estratigráfico de la excavación, parece bastante claro que su construcción no puede ser anterior al siglo $\mathrm{V} \mathrm{d}$. C. por la bolsada que corta. La datación de las tierras que se apoyan sobre las losas verticales ha de hacerse a partir de mediados del siglo VI d. C., o quizá más tarde, si consideramos que este nivel se formaría inmediatamente después de la construcción de la tumba para taparla, ya que por sus mismas características de estabilidad pensamos que esto sucedería inmediatamente o las grandes losas se hubieran desmoronado en poco tiempo.

Ha sido problemático encontrar paralelismos a esta tumba colectiva. La bibliografía que hemos cotejado no nos muestra ningún caso idéntico, aunque algunos tengan cierta semejanza. Las tumbas de grandes losas son normales en varios yacimientos contemporáneos, como en la necrópolis de la basílica de Saint Just, de Lyón (REYNAUD, 1986, 70), pero todo lo más contienen dos personas, y en la acrópolis de Cástulo, por ejemplo, hay un cementerio definido como visigodo en donde también encontramos tumbas formadas por grandes losas reutilizadas que se asientan sobre construcciones romanas (BLÁZQUEZ, 1984, 406, f. 17). Es decir, que se conocen bastantes sepulturas semejantes a estas que acabamos de enumerar, tanto en Hispania como en las Galias, pero en ningún caso hemos encontrado un paralelismo exacto con la de la calle del Mar. Normalmente, estamos ante tumbas de menor tamaño, realizadas con más cuidado, y el número de individuos no pasa nunca de tres, como ocurre también en Els Xarcons (Montserrat, Valencia), que dio una sepultura de losas grandes con los restos de tres individuos en el interior (PLA, 1961). En las excavaciones que el SIAM ha realizado (1985-86) en l'Al-

(3) Información facilitada por M. D. Sánchez de Prado, a quien agradecemos su colaboración en la clasificación de esta pieza. 

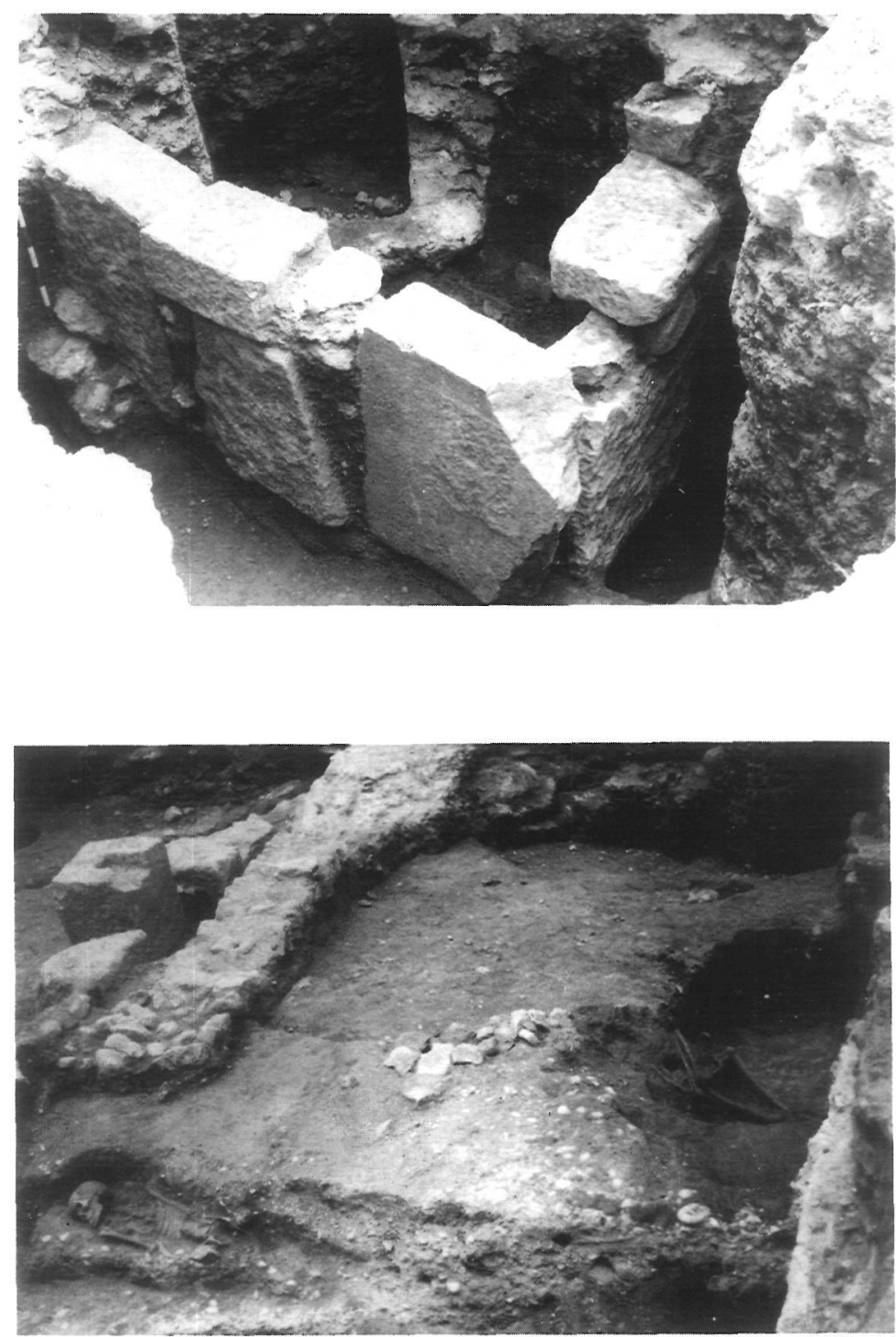

Lám. IV.-1: Vista exterior, desde el Norte, del enterramiento colectivo de la calle del Mar. 2: enterramientos de la calle del Mar (1983). Sector E.

moina se excavó una tumba de grandes losas y se localizaron otras dos que están pendientes de futuras campañas, aunque también presentan un aspecto mucho más cuidado. La que se excavó dio los restos de tres individuos. Hay noticias de otra tumba semejante en la calle del Almudín (BELTRÁN, 1972). A la necrópolis de $1^{\prime}$ Almoina también pertenecen una fosa colectiva con un número indeterminado de individuos y otras sepulturas individuales de tipología más corriente (tégulas, fosas...) y se puede datar entre los siglos VI y VII. Se encuentra claramente relacionada con una estructura absidal que, sin muchos problemas, se podría adscribir al grupo episcopal, si además tenemos en cuenta una serie de hallazgos epigráficos y arquitectónicos anteriores (LLOBREGAT, 1977b, 24-27, 31-33).

Tenemos más noticias sobre otras sepulturas colectivas de Valencia que seguramente también sean de época tardoantigua. Una habla de la tumba $n .^{\circ}$ 9 de la necrópolis del Portal de Russafa, en la que parece ser se hallaron los restos revueltos de, por lo menos, nueve personas. Se trataba de una fosa rodeada de piedras redondeadas blanqueadas y cubiertas por una gruesa capa de mortero. Se indica 
que quizá hubiera dos fases dentro del enterramiento, ya que en su base se diferenció claramente una inhumación adulta más completa y orientada de Oeste a Este. En la Boatella se hallaron también dos osarios semajantes, pero realizados con mejor técnica constructiva (LLORCA, 1962, 114). Pero los datos que hasta el momento tenemos sobre estas últimas sepulturas son bastante escuetos y, por lo tanto, no permiten que conozcamos bien ni su cronología ni su morfología exacta.

Por último, creemos que puede ser intersante recordar que las fuentes escritas del periodo visigodo en Hispania nos hablan de fuertes y frecuentes epidemias a lo largo del siglo VI y parte del VII (GROS$\mathrm{SE}, 1947,208,295,359)$, con especial referencia a la que de Hispania pasó al Sur de las Galias en el año 588, por vía marítima (FEVRIER, 1986, 23). Quizá todos o algunos de estos osarios colectivos se pudieran relacionar con estas calamidades. Esto explicaría la existencia de estas tumbas múltiples tan anómalas para la época, ya que coinciden cronológicamente con las referidas epidemias.

Asimismo, dos enterramientos individuales de la calle del Mar, poco cuidados y de una fecha semejante, también encajan con esta posibilidad. Aparecieron a unos $6 \mathrm{~ms}$. al Sureste de la sepultura colectiva (sector E) (lám. IV, 2). Uno de ellos descansaba sobre una fosa de forma irregular rellena de tierras muy negras. Apareció completo a excepción del cráneo, que seguramente desaparecería al construirse un pozo medieval. Estaba recostado hacia el lado derecho con las dos manos entrelazadas. Su orientación era Sur-Norte, con una ligera inclinación de su eje hacia el Este, mirando el cuerpo al Sureste. Estaba colocado con poco cuidado sobre el relleno de una fosa, seguramente de desperdicios, de forma muy irregular, construcción esta muy habitual en los niveles de la Antigüedad tardía en Valencia. La tierra que cubría los huesos era similar a la del relleno de la fosa y en ella aparecieron bastantes fragmentos de clara $\mathrm{D}$, entre los que predominaba casi exclusivamente la forma Hay. 99, típica del siglo VI (ATLANTE, 1981, 109-110).

Al Sureste, a unos $3 \mathrm{~ms}$. del anterior enterramiento, apareció otro similar, aproximadamente con la misma orientación. Se asentaba sobre un nivel de gravas pertenecientes, seguramente, a una avenida fluvial que tuvo lugar a fines del siglo II o inicios del III (CARMONA, RIBERA y LERMA, 1985), aunque sus pies descansaban sobre la misma fosa que la anterior sepultura. Esta fosa cortaba clara- mente el nivel de gravas. Yacía en decúbito supino con el cráneo inclinado hacia la derecha, es decir, hacia el Este. La capa de tierra que lo cubría era similar a la del enterramiento anterior. Según los datos aportados por la excavación, creemos que se podría datar estas sepulturas a partir del siglo VI d. C., fecha que viene dada por los fragmentos de clara $\mathrm{D}$ de la forma Hay. 99, lo que viene a coincidir con la sepultura colectiva. Estos dos enterramientos no parece ser que fueran depositados con excesivo ciudado, aunque al tener la misma orientación, situarse prácticamente el uno al lado del otro, estar cubiertos por la misma capa de tierras y asentarse sobre la misma fosa, podemos pensar que estamos ante una deposición simultánea e intencionada. Además, su relación cronológica con la cercana estructura sepulcral múltiple parece confirmarlo, así como la existencia de otro enterramiento que tal vez también es coetáneo y que pasamos a describir.

A unos 20 ms. en dirección Suroeste, en el solar colindante, excavado dos años más tarde (1985), se descubrió otro enterramiento (lám. V). Estaba en la parte Suroriental (sector C), a muy poca profundidad, inmediatamente por debajo de estructuras constructivas muy recientes. Se encontraba formado por una fosa irregular, pero adaptada al tamaño del inhumado. A modo de cubierta, contaba con una serie de piedras sin labrar de diversas medidas, estando las más grandes sobre el esqueleto, pero sin cubrir la cabeza, repartiéndose las demás por la parte superior del cuerpo y los lindes de la fosa. Su interior lo componía un relleno de tierra arcillosa de color marrón oscuro que apenas dio algunos materiales nada significativos. La fosa estaba excavada sobre un depósito de tierras oscuras, presentando una forma irregular, más o menos rectangular. Su anchura media era de $50 \mathrm{cms}$., mientras alcanzaba los $150 \mathrm{cms}$. de longitud. En su interior estaba depositado el esqueleto de una persona adulta en posición decúbito lateral derecho, mirando hacia el Sureste. Su eje presentaba una orientación SuresteNoroeste, aproximadamente a unos $228^{\circ}$ Norte. Conservaba todos los huesos a excepción de los pies y la mano izquierda. Su estado de conservación era aceptable.

Este tipo de enterramiento tan simple corresponde al tipo II de Gagnière (1965) de las sepulturas del Bajo Valle del Ródano, aunque claramente no se ajusta a la cronología que se le da a este tipo en el Sur de Francia. Para establecer su fechación tendremos que basarnos en varias observaciones. Por una 

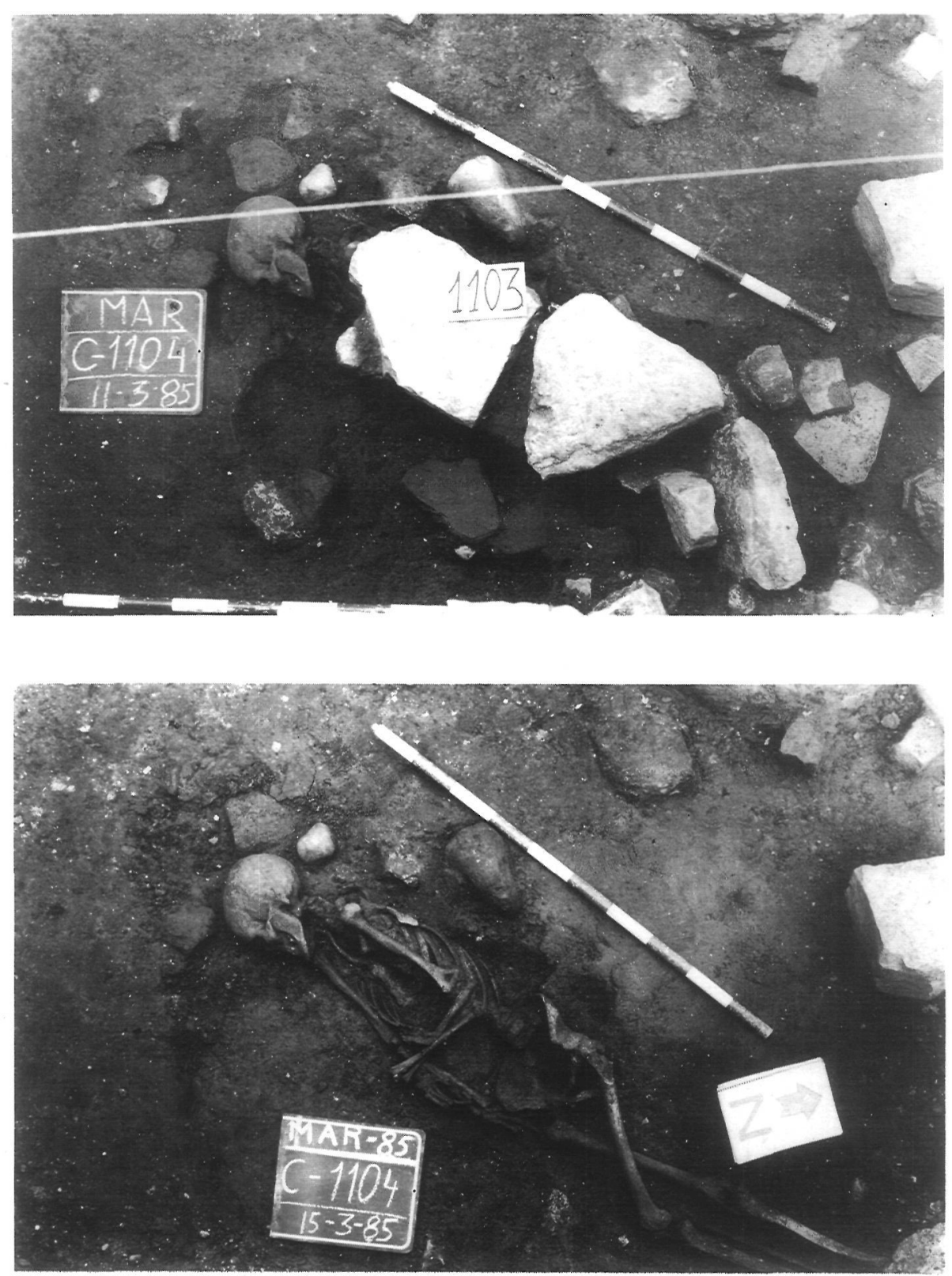

Lám. V.-Enterramiento de la calle del Mar (1985). Sector C.

parte, hay que tener en cuenta que se asienta sobre unos niveles de relleno (¿basurero?) que han dado fragmentos cerámicos que parecen llegar a fines del siglo VI d. C. (clara D, forma Hay. 90,4) (ATLANTE, 1981, 97). Por otra parte, es evidente que por su orientación no estamos ante una sepultura islámica. Lo más probable es que fuera enterrado a fines del siglo VI d. C. o, más bien, en el siglo VII d. C. La existencia de los restos de un edificio posi- blemente coetáneo puede relacionarse con estas sepulturas, y viceversa.

Lo anteriormente expuesto cobra más valor si repasamos algunos paralelos dentro de la Península. Así, en la necrópolis de Saelices, fechada a mediados del siglo VII d. C., encontramos bastantes inhumaciones en fosas cubiertas irregularmente por piedras de tamaño variado, varias de las cuales (sepulturas $3,6,9,20,22,26,73$ ) presentan una orien- 
tación similar a esta última de la calle del Mar, aunque la predominante es la Este-Oeste, como sucede normalmente en los cementerios de época visigoda (ALMAGRO, 1975). En una necrópolis cercana a Complutum podemos ver también fosas muy similares que guardan una orientación parecida y que también se datan en el siglo VII d. C. (FERNÁNDEZ, 1976). Lo mismo sucede en la necrópolis de la Pedrera (Sevilla) (FERNÁNDEZ et alii, 1984), por no citar más casos. Sin embargo, dentro del País Valenciano no disponemos de paralelos tan evidentes ante la falta de publicaciones de necrópolis de esta época. Los casos más parecidos son los de «les Jovades» (Cocentaina, Alicante), concretamente su tumba 4, que se ha datado, como todo el conjunto, a fines del siglo VI o inicios del VII d. C. (LLOBREGAT, 1977c), y el de la tumba 9 de la necrópolis de Gaià (Pego, Alicante), que presenta una datación similar (GISBERT, 1983).

Con todo, no es claro que esta última sepultura de la calle del Mar sea sincrónica a las tres anteriores, ya que su ejecución era distinta y se asentaba sobre un nivel que parecía similar al que cubría a los restantes enterramientos. Quizá haya que datarla hacia el siglo VII, que es donde encontramos los paralelos más cercanos.

El cementerio de la calle del Mar tal vez se extendería un poco hacia el Sur, ya que tenemos noticias poco explícitas de la aparición de restos humanos en la calle Castelvins, perpendicular a la calle del Mar, a la altura del solar afectado por las excavaciones.

La presencia de esta necrópolis plantea, en primer lugar, el problema de su situación topográfica. Aunque en esta misma excavación hemos constatado que la ciudad romana perdura aquí, por lo menos, hasta el siglo $\mathrm{V}$, no sabemos a ciencia cierta si estamos dentro o fuera del recinto de la ciudad coetánea a los enterramientos, de la que sólo se han hallado restos evidentes hacia el Norte (l'Almoina). No sería extraño que después de una probable reducción del perímetro de la ciudad romana imperial este área quede fuera del recinto y sea ocupada por cementerios, aunque no es en absoluto descartable el que esta necrópolis quede dentro de la ciudad en época visigoda, como ocurre en Barcelona (BALIL, 1964, 57), Cástulo (BLÁZQUEZ, 1984, 406) y en otras muchas ciudades hispanas durante la antigüedad tardía (GARCÍA MORENO, 1977-78; BARRAL, 1982). Mientras no conozcamos los límites de la ciudad, no tendremos la posibilidad de aclarar esta cuestión. Lo evidente es que en la superficie excavada sólo se hallaron muros de la época que tratamos en la parte meridional del solar, mientras en el resto fue normal encontrar bastantes fosas que cortaban estructuras romanas y que estaban colmatadas por tierras muy negras con restos de desperdicios y hogueras en las que se recogió material del siglo VI d. C., como ya hemos indicado. $\mathrm{Al}$ menos tres de los enterramientos estaban relacionados cronológicamente con este estrato, mientras que el otro y los muros que acabamos de mencionar se asentaban sobre estas capas o posible basureros. Dado lo poco que se ha conservado del mencionado muro a causa de las fuertes intrusiones medievales y modernas, no podemos saber si se trata de algún edificio relacionado con los enterramientos o tal vez un poco posterior. En este sentido, tenemos que señalar que muy cerca de la excavación se encuentra un capitel de clara filiación tardía, precisamente en uno de los lugares que se conoce como la cárcel de Sant Vicent.

\section{LA NECRÓPOLIS DE VALENTIA}

Las continuas excavaciones que se vienen realizando en el casco antiguo de Valencia no cesan de deparar nuevos y preciosos datos para realizar un completo estudio arqueológico de la ciudad. Pero, debido a la dinámica propia de la arqueología urbana, los trabajos de excavación vienen condicionados por las necesidades del desarrollo urbanístico, y, en este caso concreto, de la rehabilitación del centro histórico.

En este contexto, el estudio de las necrópolis romanas también está limitado por una serie de carencias de conocimiento. La falta de datos sobre el recorrido exacto de la Vía Augusta a su paso por la ciudad es una de las premisas que impiden saber la posible ubicación de las necrópolis, especialmente las de la primera época de la ciudad. Así, de la etapa republicana, la más desconocida arqueológicamente, no tenemos ningún dato sobre su zona de enterramientos. Casi lo mismo podemos decir de los dos primeros siglos de nuestra Era, época a la cual tal vez pertenezcan unos enterramientos aparecidos hace varios años en la calle Barcelonina, en la calle de la Paz y en el edificio del actual Ayuntamiento. Pero en todos estos casos estamos ante informaciones confusas, las más de ellas de carácter oral. No obstante, su situación topográfica dentro de lo que 
sabemos fue la ciudad romana imperial puede concordar fácilmente con esta suposición.

Al igual que sucede en el resto del País Valenciano (4), es a partir del finales del siglo II o inicios del III cuando tenemos datos fehacientes de necrópolis situadas claramente en áreas cercanas a límites urbanos. El hallazgo más importante ha sido el del cementerio de la Boatella, aparecido en 1945, y que fue objeto de largas campañas de excavaciones desde esa fecha hasta 1963. En conjunto se encontraron unas 250 inhumaciones, la mayor parte de $\epsilon_{i}$ las sin ajuar y formadas por estructuras de tégulas y ladrillos (CUEVES, 1948), aunque también hay un sarcófago de piedra con tapadera, un mosaico sepulcral y varias ánforas utilizadas como enterramientos infantiles (FERNÁNDEZ, 1984, 2528). Los ajuares eran escasos y pobres (ARANDA, 1948), con una sola pieza por sepultura, y normalmente estaban compuestos por una jarra de cerámica común o, más frecuentemente, por vasijas de vidrio. También se conocen unos pocos ejemplares de clara A (RIBERA, 1983, fs. 7 y 8). Su datación se puede precisar en base al estudio de estas pocas piezas. La clara A (formas Lamb. 3 y Hay. 121) nos lleva a un momento posterior a fines del siglo II d. C., fecha coincidente con la del numeroso grupo de vidrios. Del mismo modo, la cerámica común parece apuntar hacia unas fechas centradas en el siglo III d. C., como han demostrado una serie de contextos arqueológicos de otros lugares de la ciudad, especialmente el relleno de una cloaca de la calle del Mar, que se pudo fechar con toda claridad en la segunda mitad del siglo III d. C. Con todo, existen indicios que señalan que se continuaría enterrando en esta zona durante el siglo siguiente o algo más tarde, como parece demostrarlo la presencia de un mosaico sepulcral en el extremo Norte del área excavada. Hay que destacar que el estudio en profundidad de esta importante necrópolis aún no se ha podido realizar, como hubiera sido nuestro deseo, ya que es una de las excavaciones que más información pueden aportar para resolver el problema que plantean los cementerios urbanos de Valentia. Afortunadamente, pronto se tendrá la ocasión de realizar excavaciones con la técnica adecuada en un solar que con toda seguridad está incluido dentro de esta área cementerial.

(4) Según información facilitada por $\mathrm{R}$. Villaescusa, que se encuentra realizando un amplio estudio sobre las necrópolis romanas en el País Valenciano.
Hasta el momento, la única necrópolis de Valentia publicada ha sido la del Portal de Russafa (LLORCA, 1962), que, según muestran sus tipos de tumbas y ajuares, debe ser coetánea con la época de apogeo de la Boatella. Además, presenta claros paralelismos con otros enterramientos de la comarca de la Ribera del Xùquer, como los de «les Foies» (Manuel) (SENTANDREU, 1966) o los de Tisneres (Alzira) (5), que se datan en el mismo momento cronológico. Al igual que éstas, a la del Portal de Russafa se le atribuyó un carácter rural debido a su aparente lejanía de la ciudad romana. Los recientes estudios sobre ésta nos llevan a plantear en el período imperial una probable expansión urbana hacie el Sur (DIES, ESCRIBÁ y RIBERA, en prensa), con lo que podría contradecir su pretendido carácter de cementerio rural, ya que los probables límites de la ciudad estarían aproximadamente a unos $250 \mathrm{~ms}$. No sería extraño, pues, que estuviéramos ante una necrópolis meridional, aunque de toda esta área los datos arqueológicos que tenemos son muy escasos. La Boatella se podría considerar como parte de una supuesta necrópolis occidental que se extendería aún más hacia el Norte. Estas dos áreas de enterramientos presentan la particularidad común de estar situadas al otro lado del antiguo brazo del río que envolvía la ciudad. Indicios claros de otras zonas de enterramiento no se conocen para la época imperial, aunque se puede señalar una ligera concentración de epigrafía funeraria hacia la mitad de la actual calle de la Paz (PEREIRA, 1979, n. ${ }^{\circ} 24,25$, $30,31,52$ ), lo que viene a coincidir con el hipotético límite Este de la ciudad y probablemente con el camino que llevaría al Mar, pero hay que tener en cuenta que también estamos hablando de otra zona poco explorada arqueológicamente. Aún más desconocida, si cabe, es la zona Norte, al otro lado del Turia, en la que no sería raro que también se ubicaran necrópolis romanas, ya que, además, es la zona de paso de la Vía Augusta y, como hemos visto, 2 $\mathrm{kms}$. al Norte, en el siglo IV d. C. se alzaba un mausoleo. Esto es cuanto se puede decir de las necrópolis de la ciudad en el período de la dominación romana, del que sólo tenemos información clara para el siglo III d. C., mientras que tanto las etapas anteriores como el siglo siguiente son especialmente oscuros en los aledaños de la ciudad, siendo la Boate-

(5) Datos proporcionados por R. Villaescusa, a quien de nuevo agradecemos su colaboración. 
lla la única que puede presentar restos del siglo IV d. C.

Ya fuera del área estrictamente urbana, conocemos para el siglo IV d. C. los dos casos que ya hemos examinado con detalle. En la zona Norte, junto a la Vía Augusta, tenemos el mausoleo de Orriols. Su ubicación plantea problemas interpretativos al desconocerse completamente sus alrededores, por lo que no se puede saber si pertenece a un grupo más amplio, como Centcelles, o si se trata de un elemento aislado. El caso de la Roqueta plantea otro tipo de problemas más concretos, ligados a la existencia de un probable centro de culto martirial dedicado a Sant Vicent y que sólo se podrá resolver definitivamente realizando excavaciones dentro de la iglesia y en su patio Sur.

La evidencia arqueológica sólo la volvemos a encontrar en el siglo VI d. C. con cementerios que ocupan áreas urbanas. A primera vista, se diferencian claramente dos tipos de tumbas. Uno, al que pertenecen la mayoría de los enterramientos de la calle del Mar, uno de l'Almoina y otros de «els Banys de l'Almirall», está formado por inhumaciones depositadas con poco orden y cuidado, $y$ tanto son individuales como colectivas. Las fuentes hablan (GROSSE, 1947, 208, 295, 259) de frecuentes epidemias a lo largo del siglo VI y finales del VII d. C., que tal vez sirvan para explicar estos hallazgos. El otro grupo está formado por sepulturas más cuidadas, de las que se conocen muchos paralelos. Aquí podemos incluir la mayoría de los enterramientos de l'Almoina y una fosa de la calle del Mar. Normalmente se trata de inhumaciones individuales, aunque también se han señalado tres individuos en grandes tumbas formadas por losas de buen tamaño. El carácter de esta necrópolis, que aún está pendiente de su total excavación y estudio detallado, hay que relacionarlo con su inmediatez a lo que debió ser el centro episcopal de la ciudad, al menos desde los siglos VI y VII d. C., como lo demuestran los restos epigráficos conocidos de antiguo (LLOBREGAT, 1977b, 24-27), lo cual se ha visto recientemente corroborado por el hallazgo de un ábside datable por estas fechas y con el que se encuentran claramente relacionados los enterramientos.

Este panorama general que hemos tratado de esbozar esperamos que se pueda ir ampliando y precisando por medio del estudio de materiales aún inéditos, en especial de la Boatella, y de las excavaciones que se están realizando en la ciudad de Valencia, caso de la mencionada Almoina y de algunas otras pendientes de ejecución, sobre todo en Sant Vicent de la Roqueta y en la misma Boatella.

\section{APÉNDICE}

\section{RESUMEN DEL ESTUDIO ANTROPOLÓGICO}

\section{SANT VICENT DE LA ROQUETA (6)}

En el interior del ataúd de plomo hallado en la cata $D$ se encontraba un esqueleto en posición de decúbito supino. Su estado de conservación no era muy bueno debido a que estaba aplastado por el peso de la tierra que colmataba el ataúd. La cabeza está fragmentada y tocando una de las paredes del sarcófago.

La longitud esquelética, talón-cráneo, es de 155 cms. y la posición de los restos de las primeras vértebras cervicales y los fragmentos craneales hacen suponer que su altura era un poco mayor, entre 1,60 y $1,65 \mathrm{~ms}$.

El estudio de los fragmentos craneales da como resultado:

Glabela inexistente, sin relieve. Cavidades orbitarias de bordes finos, casi cortantes. No existe criba orbitaria. Arcos supraorbitarios sin relieve. Las apófisis mastoideas son pequeñas. No hay proceso cigomético posterior supraauditivo. Cavidades glenoideas mandibulares pequeñas. Paladar excavado y parabólico con un molar atrófico, el tercero izquierdo. Mandíbula de tamaño medio, con gonions rectos, no evertidos, de aspecto grácil, condelas poco robustas. Los dos incisivos derechos del maxilar superior estaban sueltos, al igual que los tres molares de la mandíbula, pero encajaban en sus agujeros. El tercer molar izquierdo del maxilar es de reducido tamaño, como atrófico. La usura dental oscila entre dos y casi tres en todas las piezas.

Con las debidas reservas, ya que los datos craneales para determinar el sexo son bastante secundarios, podemos catalogar estos restos como perte-

(6) Datos proprocionados por F. Puchalt, que se encuentra efectuando un estudio de todos los restos óseos aparecidos en Sant Vicent de la Roqueta. 
necientes al sexo femenino, pudiéndosele adjudicar una estatura entre 1,60 y $165 \mathrm{~ms}$. Dada la existencia de terceros molares, es posible catalogar estos restos como pertenecientes a un adulto.

\section{CALLE DEL MAR (1981-83) (7)}

Nos encontramos ante un grupo heterogéneo de restos óseos pertenecientes a 13 individuos, de los que 8 son varones adultos, de edades comprendidas entre los 20 y los 60 o más años, aunque el promedio de edad es de alrededor de 25 años. El grupo incluye también a tres mujeres, de las que dos se encontraban en la edad media de la vida (35 a 40 años) y una era aún joven (menos de 25 años), Por último, había también un joven adolescente de unos 10 años de edad y un niño de 3 a 4 años.

La primera conclusión que se impone es que se trata de un grupo humano de marcado carácter civil por la presencia de mujeres y niños.

Desde el punto de visto antropológico, se puede señalar una preponderancia de dolicocefaleas $(33 \%)$ sobre la braquicefalia $(16,6 \%)$ y la mesaticefalia $(8,3 \%)$. Se trata de datos que demuestran una variabilidad racial bastante frecuente en toda la cuenca mediterránea.

Las estaturas se sitúan entre valores medios para las mujeres de 1,55 ms. Los varones, en las pocas medidas que se han podido tomar, arrojan estaturas de $1,65 \mathrm{~ms}$. en un caso y 1,75 ms. en otro, siendo esta última una talla notable para esta época.

Los escasos restos de piezas dentarias presentan como dato interesante el hecho de carecer de caries, lo que indicaría una relativamente buena salud dental. Las abrasiones son, en cambio, bastante marcadas desde los 20 años de edad, sin diferencias sexuales, todo lo cual habla de una dieta igualitaria en la que debían de ser frecuentes las harinas molidas y los frutos secos, así como las verduras y frutas frescas.

Desde el punto de vista paleopatológico, cabe señalar que no se evidencian signos de traumatismos, malformaciones congénitas o enfermedades infecciosas, endocrinas o tumorales. Únicamente en un esqueleto de varón de edad superior a los 60 años se aprecian signos degenerativos articulares que no nos atreveríamos a clasificar como patológicos, sino

(7) Según informe redactado por F. Gómez Bellard. más bien como cambios propios de la edad avanzada del sujeto.

Por último, indicaremos que no es posible determinar las causas de muerte en estos restos óseos. Sólo podemos decir que no es probable que las muertes fueran simultáneas, por causa violenta, no pudiéndose descartar, en cambio, la acción de agentes infecciosos de tipo epidémico.

\section{CALLE DEL MAR (1985) (8)}

En el sector C de esta campaña apareció en el interior de una fosa un esqueleto completo, de sexo femenino por el aspecto de la escotadura ciática d ela pelvis.

Se observa un reborde vertebral en gran parte de las piezas de la columna. Esto nos determina la edad, alrededor de 40 años, ya que este proceso es visible a partir de los 35-40 años. Correspondería a una mujer de $1,49 \mathrm{~ms}$. de altura. Se observa una glabela poco saliente, protuberancia occipital poco acusada, sin rastros de inserciones musculares potentes. Los arcos supraciliares son poco marcados y las apófisis mastoideas tienen pequeñas dimensiones. La mandíbula es fina, de aspecto grácil, condelas pequeñas, mentón saliente y gonions no evertidos. Se observa un torus palatino y un agujero occipital con una escotadora en la parte posterior izquierda de borde liso, no astillado, en el que no asoma el hueso esponjoso. Su significado es, hoy por hoy, incierto, ya que podemos descartar que se hubiese efectuado «post-mortem». La usura dentral es muy variada, oscilando entre tres-cuatro del tercer molar mandibular derecho y tres en todas las demás piezas.

Como resumen, podemos decir que es un esqueleto femenino de unos 40 años de edad, cuya longitud del húmero derecho correspondería hoy, en una mujer de raza blanca, a una persona de 1,49 de altura.

Presenta patología dentaria en ambos lados de la mandíbula, siendo el estado dental de las piezas restantes muy deficiente por la abrasión. El paladar presenta un torus bien constituido y el agujero occipital es de contorno irregular por la presencia de una especie de escotadura, cuyo significado es todavía incierto.

(8) Información proporcionada por F. Puchalt, a quien manifestamos nuestro agradecimiento. 


\section{BIBLIOGRAFİA}

ALMAGRO, M. 1975: «La necrópolis hispano-visigoda de Saelices (Cuenca). Excavaciones Arqueológicas en España, 84.

ARANDA, C. 1948: «Ajuar funerario de la necrópolis de la Boatella». III Congreso Arqueológico del Sureste Español, 271-274.

ATLANTE (V.V.A.A.). 1981: «Atlante delle forme ceramiche I. Ceramica fina romana nel bacino Mediterraneo (medio e tardo impero)». Enciclopedia dell'Arte Antica.

BALIL, A. 1959: «Sarcófago romano del Levante español. (Contribución al estudio de los sarcófagos de plomo en el mundo romano)» Revista de Guimaraes, 69, 303-375.

- 1964: «Colonia Ivlia Avgvsta Paterna Faventia Barcino». Bibliotheca Archaeologica, IV.

BARRAL, X. 1982: «Transformacions de la topografia urbana a la Hispània cristiana durant l'antiguitat tardana». II Reunió d'Arqueologia Paleocristiana Hispànica, 105-132.

BELTRÁN, P. 1972: «Hallazgos de lápidas romanas en Valencia». Monografías Arqueológicas, 11, 700-707.

BLAZZUEZ, J. 1984: «Castulo, capital of the mining district of Oretania». B. A. R. Intern. Series, 193, 396-409.

CARMONA, P.; RIBERA, A., y LERMA, J. 1985: «Geoarqueología en la ciudad de Valencia». XVII Congreso Nacional de Arqueología, 859-873.

CASTELL, V. 1973a: «Sant Vicent de la Roqueta llar espiritual de Valencia». Las Provincias, 30 de octubre, 11.

- 1973b: «Sant Vicent de la Roqueta llar espiritual de Valencia». Las Provincias, 2 de noviembre, 17.

CORTÉS, J., y PALOL, P. 1974: «La villa romana de la Olmeda». Acta Arqueológica Hispánica, 7.

CORTÉS, R. 1981: «Excavacions al carrer de Pere Martell. Butlletí Arqueològic de la Reial Societat Arqueològica Tarraconense, 3, 126-140.

CUEVES, D. 1948: «Elementos constructivos romanos encontrados en la necrópolis de la Boatella de Valencia». III Congreso de Arqueología del Sureste Español, 275-278.

CHABÁS, R. 1904: Homenaje a San Vicente Mártir, Valencia.

- 1909: Episcológico valentino, Valencia.

DEL AMO, M. D. 1979: Estudio crítico de la necrópolis paleocristiana de Tarragona, Tarragona.

DIES, E.; ESCRIVÁ, V., y RIBERA, A. (en prensa): «Ampliació urbana de Valentia a partir de l'época flavia». I Jornades Internacionals d'Arqueología Romana, Granollers.

EPALZA, M., y LLOBREGAT, E. 1982: «¿Hubo mozárabes en las tierras valencianas? Proceso de islamización del Levante de la península (Sharq al-Andalus)»s Revista del Instituto de Estudios Alicantinos, 36, 1-31.

FERNÁNDEZ GALIANO, D. 1976: «Excavaciones en la necrópolis hispano-visigoda del Camino de los Afligidos (Alcalá de Henares). 1975». Noticiario Arqueológico Hispánico, 4, 5-90.

FERNÁNDEZ IZQUIERDO, A. 1984: «Las ánforas romanas de Valentia y de su entorno marítimo». Serie Arqueológica del Ayuntamiento de Valencia, 3.

FERNÁNDEZ, F.; OLIVA, D., y PUYA, M. 1984: «La necrópolis tardorromana-visigoda de 'Las Huertas' en Pedrera (Sevilla)». Noticiario Arqueológico Hispánico, 19, 271-387.

FEVRIER, P. A. 1986: «Approches de la Gaule Méridionale. Le poids du passé et la Christianisation». Premiers temps chrétiens en Gaule Méridionale, 16-29.

FLETCHER, D., y PLA, E. 1952: «Arqueología de la comarca de Sollana (Valencia). Anales del Centro de Cultura Valenciana, XX, 1-13.
FOY, D., y BONIFAY, M. 1984: «Éléments d'évolution des verreries de l'Antiquité tardive à Marseille d'après les fouilles de la Bourse (1980)». Revue Archéologique de Narbonnaise, 17, 289-308.

GAGNIÈRE, S., 1965: «Les sépultures à inhumation du IIIème au XIII éme siècle de notre ère dans la Basse-Vallée du Rhône. Essai de chronologie typologique. Cahiers Rhodaniens, XII, 53-110.

GARCÍA, A. 1984: «L'enigma històric de Sant Vicent de la Roqueta». L'Espill, 9, 113-126.

GARCÍA Y BELLIDO, A. 1960: Colonia Aelia Avgvsta Itálica. Bibliotheca Archaeologica, II.

GARCÍA MORENO, L. 1977-78: «La cristianización de la topografía de las ciudades de la península Ibérica durante la antigüedad tardía». Archivo Español de Arqueología, 5051, 331-321.

GISBERT, J. 1983: «La necrópolis romano-tardía de la partida de Gaià (Pego, Alacant). Puntualizaciones sobre su ajuar y cronología». Revista del Instituo de Estudios Alicantinos, 39, 157-175.

GÓMEZ SERRANO, N. P. 1941: «Arqueología de los refugios de Valencia». Las Provincias. Almanaque para 1941, 487-491.

GROSSER, R. 1947: «Las fuentes de la época visigoda y bizantina». Fontes Hispaniae Antiquae, IX.

HAUSCHILD, T. 1982: "Técnicas y maneras de construir en la arquitectura paleocristiana hispánica». II Reunió d'Arqueologia Paleocristiana Hispànica, 71-86.

HAYES, J. 1977: «North African flanged bowls. A problem in fifth century cronology». B. A. R. Supplementary Series, 30, 279-287.

ISINGS, C. 1957: Roman Glass from dated finds. Groningen/Djakarta.

LEPAGE, C. 1971: «Les bracelets du luxe romains et byzantins du II au VI siècle. Étude de la forme et de la structure». Cahiers Archéologiques fin de l'Antiquité et Moyen Age, 21.

LLOBREGAT, E. 1977a: «San Vicente Mártir y Justiniano de Valencia». Homenaje a Fray Justo Pérez de Urbel, 2, Silos.

- 1977b: «La primitiva cristiandat valenciana». Valencia.

- 1977c: «Enterramientos de época romana tardía en Cocentaina (Alicante). Segovia y la Arqueología romana, 257-264.

LLORCA, J. 1962: «Hallazgo de una necrópolis romana en el antiguo Portal de Ruçafa». Papeles del Laboratorio de Arqueología de Valencia, 1, 111-115.

MARTÍNEZ ALOY, J. s. a.: Geografía del Reino de Valencia. Valencia.

MOROTE, G. 1986: «El Albir». Arqueología en Alicante 19761986. Instituto de Estudios Juan Gil Albert, 57-60.

PALOL, P. 1967: Arqueología cristiana de la España Romana. siglos IV-VI. Instituto Enrique Flores, Valladolid-Madrid.

PEREIRA, G. 1979: Inscripciones romanas de Valentia. Trabajos varios del S. I. P., 64, Valencia.

PLA, E. 1961: «Actividades del S. I. P. (1956-1960)». Archivo de Prehistoria Levantina, IX, 211-253.

REYNAUD, J, 1981: «Lyon du IV siècle au VIII siècle; édifices religieux, nécropoles et topographie urbaine». B. A. R., $108,119-156$

- 1986: «Lyon aux premiers temps chrétiens: basiliques et nécropoles». Guides Archéologiques de la France, 10.

- COLARDELLE, R.; COLARDELLE, R.; JANNET-VALLAT, M.; PERINETTI, R., y PRIVATI, B. 1986: «Les édifices funéraires et leurs nécropoles: origines et premiers développements». Preactas del XI Congrés International d'Archéologie Chrétienne. 
RIBERA, A. 1983: La arqueología romana en la ciudad de Valentia. Informe preliminar. Serie Arqueológica del Ayuntamiento de Valencia, 1, Valencia.

SÁNCHEZ DE PRADO, M. D. 1984a: «El vidrio romano en la provincia de Alicante». Lvcentvm, III, 79-100.

- 1984b: «El vidre». València romana. Els origens de la ciutat, 39-40.

SANCHIS SIVERA, J. 1920: «La diócesis valentina». Anales del Instituto General y Técnico de Valencia, Valencia.

SANMARTÍN MORO, P., y PALOL, P. 1972: «Necrópolis Paleocristiana de Cartagena». VIII Congreso Internacional de Arqueología Cristiana, 447-458.
SENTANDREU, C. 1966: «La necrópolis romana de 'Les Foies' (Manuel, Valencia)». Archivo de Prehistoria Levantina, XI, 197-202.

SERRA VILARO, J. 1932: Excavaciones en Tarragona. Memoria de la Junta Superior de Excavaciones y Antigüedades, 116, Madrid.

SOTOMAYOR, M. 1975: Sarcófagos romano-cristianos de España. Estudio iconográfico. Facultad de Teología de Granada. 